Article

\title{
Design, Synthesis, and In Vitro Evaluation of Hydroxybenzimidazole-Donepezil Analogues as Multitarget-Directed Ligands for the Treatment of Alzheimer's Disease
}

\author{
Sílvia Chaves ${ }^{1}{ }^{1}$, Simonetta Resta ${ }^{1,2}$, Federica Rinaldo ${ }^{1,2}$, Marina Costa ${ }^{1}\left(\mathbb{D}\right.$, Romane Josselin ${ }^{1}$, \\ Karolina Gwizdala ${ }^{1}$, Luca Piemontese ${ }^{2}{ }^{\oplus}$, Vito Capriati ${ }^{2,3}{ }^{\circledR}$, A. Raquel Pereira-Santos ${ }^{4,5}$, \\ Sandra M. Cardoso ${ }^{4,5}$ and M. Amélia Santos $1, * \mathbb{D}$ \\ 1 Centro de Química Estrutural and Departamento de Engenharia Química, Instituto Superior Técnico, \\ Universidade de Lisboa, Av. Rovisco Pais, 1049-001 Lisboa, Portugal; silvia.chaves@tecnico.ulisboa.pt (S.C.); \\ s.resta7@studenti.uniba.it (S.R.); f.rinaldo@studenti.uniba.it (F.R.); marinamcosta91@gmail.com (M.C.); \\ josselinromane@gmail.com (R.J.); karo.gwizdala@gmail.com (K.G.) \\ 2 Dipartimento di Farmacia-Scienze del Farmaco, Università degli Studi di Bari “Aldo Moro", \\ Via E. Orabona 4, I-70125 Bari, Italy; luca.piemontese@uniba.it (L.P.); vito.capriati@uniba.it (V.C.) \\ 3 Consorzio C.I.N.M.P.I.S., Via E. Orabona 4, I-70125 Bari, Italy \\ 4 CNC - Center for Neuroscience and Cell Biology, University of Coimbra, 3004-504 Coimbra, Portugal; \\ araqpsantos@gmail.com (A.R.P.-S.); cardoso.sandra.m@gmail.com (S.M.C.) \\ 5 Institute of Molecular and Cell Biology, Faculty of Medicine, University of Coimbra, 3000-548 Coimbra, \\ Portugal \\ * Correspondence: masantos@tecnico.ulisboa.pt; Tel.: +351-218419273
}

Academic Editor: Diego Muñoz-Torrero

Received: 9 January 2020; Accepted: 18 February 2020; Published: 22 February 2020

check for updates

\begin{abstract}
A series of multi-target-directed ligands (MTDLs), obtained by attachment of a hydroxyphenylbenzimidazole (BIM) unit to donepezil (DNP) active mimetic moiety (benzylpiperidine/-piperazine) was designed, synthesized, and evaluated as potential anti-Alzheimer's disease (AD) drugs in terms of biological activity (inhibition of acetylcholinesterase (AChE) and $\beta$-amyloid $(\mathrm{A} \beta$ ) aggregation), metal chelation, and neuroprotection capacity. Among the DNP-BIM hybrids studied herein, the structural isomerization did not significantly improve the biological properties, while some substitutions, namely fluorine atom in each moiety or the methoxy group in the benzyl ring, evidenced higher cholinergic AChE activity. All the compounds are able to chelate $\mathrm{Cu}$ and $\mathrm{Zn}$ metal ions through their bidentate BIM moieties, but compound 5, containing a three-dentate chelating unit, is the strongest $\mathrm{Cu}(\mathrm{II})$ chelator. Concerning the viability on neuroblastoma cells, compounds 9 and $\mathbf{1 0}$ displayed the highest reduction of $\mathrm{A} \beta$-induced cell toxicity. In silico calculations of some pharmacokinetic descriptors indicate that all the compounds but the nitro derivatives have good potential oral-bioavailability. Overall, it can be concluded that most of the studied DNP-BIM conjugates showed quite good anti-AD properties, therefore deserving to be considered in further studies with the aim of understanding and treating AD.
\end{abstract}

Keywords: hydroxyphenyl-benzimidazole; donepezil; anti-neurodegeneratives; Alzheimer's disease; multifunctional drugs; metal chelation

\section{Introduction}

Alzheimer's disease (AD) is a severe age-dependent neurodegenerative disorder, with no cure so far, characterized by a drastic progressive decline in memory and cognitive abilities. With the increase of life expectancy of humans, the number of AD patients is growing dramatically and in 2050 it will be 
around 150 million worldwide [1]. In spite of all the research performed to understand and treat AD, there has been a high rate of failure in AD drug development programs [2,3]. The currently available therapies consist of acetylcholinesterase (AChE) inhibitors, such as donepezil (DNP, Aricept ${ }^{\circledR}$ ), and an $\mathrm{N}$-methyl-D-aspartate receptor (NMDAR) antagonist (memantine) [4]. However, they can only lead to some temporary enhancement of neurotransmission levels (e.g., cholinergic and glutamatergic), and so a valid therapy for $\mathrm{AD}$ remains an urgent unmet medical need. From the research efforts to understand this disease, several factors have been considered to play important roles in the pathophysiology of this illness, such as deficits of acetylcholine, $\beta$-amyloid deposits, $\tau$-protein phosphorylation, oxidative stress, and metal dyshomeostasis [5]. The disease complexity has been recognized as the main cause for clinical failures of drugs based on the individual pathogenic targets. Therefore, over the last decade, the need to design chemical tools capable of interacting with multiple pathological elements of $A D$ has prompted the scientific community and led to extensive research on multi-target-directed-ligands (MTDLs) [6-8]. Under this strategy, many multifunctional molecules have been discovered with the aim to combine the control of the symptoms with real disease modifying actions. Thus, various approved acetylcholinesterase drugs have been repositioned for further derivatizations, by enclosing or fusing other molecular entities to interact with some other AD targets, namely those related with the toxic amyloid plaque, such as the inhibition of $\beta$-amyloid $(\mathrm{A} \beta)$ fibril formation (e.g., inhibition $\beta$-Secretase, BACE-1) and its aggregation, as well as the control of effects of oxidative stress and metal dyshomeostasis, due to their recognized role in deleterious protein/peptide modification and aggregation [9-12]. In particular, several DNP derivatives have been recently developed to associate the cholinesterase inhibition with anti-oxidant capacity or with anti- $\beta$ amyloid cascade properties $[13,14]$. Also, the implication of metal ions, such as copper, zinc, and iron, has long been recognized in AD, associated to the enhancement of deleterious reactive oxygen species (ROS) in the brain $(\mathrm{Fe}, \mathrm{Cu}$ ) and to intertwined roles $(\mathrm{Cu}, \mathrm{Zn})$ in $\beta$-amyloid aggregation [15-17]. Therefore, intensive research has recently been dedicated towards the development of MTDLs enclosing metal chelating functions, as potential anti-AD drug candidates (for reviews see refs $[5,10,18,19]$ ).

This subject has also been one of the main recent aims of our research group, with MTDLs enclosing a molecular fragment based on AChEi drug (e.g., Tacrine, DNP), which has been derivatized with a variety of functional moieties, several of them including metal chelating groups (such as cysteine, hydroxypyridinone, hydroxycinamate, hydroxybenzofurane, and hydroxyphenylbenzimidazole (BIM)) [19-22]. The interesting properties revealed by the recently reported novel tacrine-hydroxyphenylbenzimidazole (TAC-BIM) hybrids [22] led to the development of other MTDL analogues, by attachment of a BIM group to DNP active mimetic ligands (benzyl-piperidine/benzyl-piperazine), to assure $\mathrm{AChEi}$, inhibition of $\mathrm{A} \beta$ aggregation and modulation of metal dyshomeostasis [23]. As a continuation of our efforts to search for new DNP-BIM hybrids, herein we present a series of analogues (see Figure 1), which aims to explore the effect of positional isomerization and introduction of a substituent on each of the above referred main multiple anti-AD properties as well as on drug-likeness prediction. Discussion is also provided by establishing comparison with previously reported DNP-BIM hybrids. 

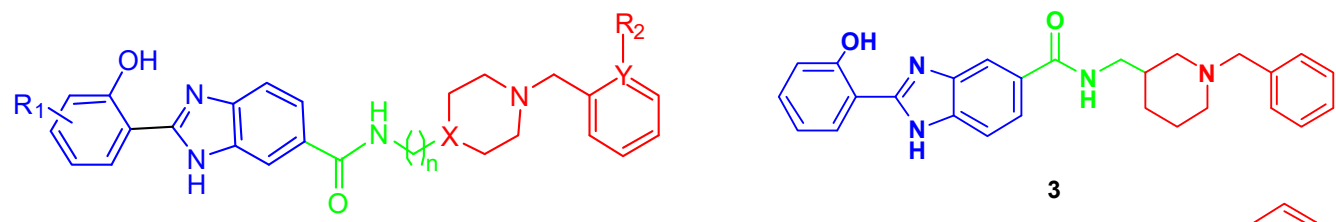

3

$\begin{array}{cccccc} & \mathrm{X} & \mathrm{Y} & \mathrm{n} & \mathrm{R}_{1} & \mathrm{R}_{2} \\ \mathbf{1} & \mathrm{C} & \mathrm{C} & 1 & \mathrm{H} & \mathrm{H} \\ \mathbf{2} & \mathrm{N} & \mathrm{C} & 2 & \mathrm{H} & \mathrm{H} \\ \mathbf{6} & \mathrm{C} & \mathrm{C} & 1 & 3-\mathrm{F} & \mathrm{H} \\ \mathbf{7} & \mathrm{N} & \mathrm{C} & 2 & 3-\mathrm{NO}_{2} & \mathrm{H} \\ \mathbf{8} & \mathrm{N} & \mathrm{C} & 2 & 3-\mathrm{F} & \mathrm{H} \\ \mathbf{9} & \mathrm{N} & \mathrm{C} & 2 & 3-\mathrm{OMe} & \mathrm{H} \\ & & & & & \\ \mathbf{1 0} & \mathrm{N} & \mathrm{C} & 2 & \mathrm{H} & 2-\mathrm{F} \\ \mathbf{1 1} & \mathrm{N} & \mathrm{C} & 2 & \mathrm{H} & 2-\mathrm{NO}_{2} \\ \mathbf{1 2} & \mathrm{N} & \mathrm{N} & 2 & \mathrm{H} & \mathrm{H}\end{array}$
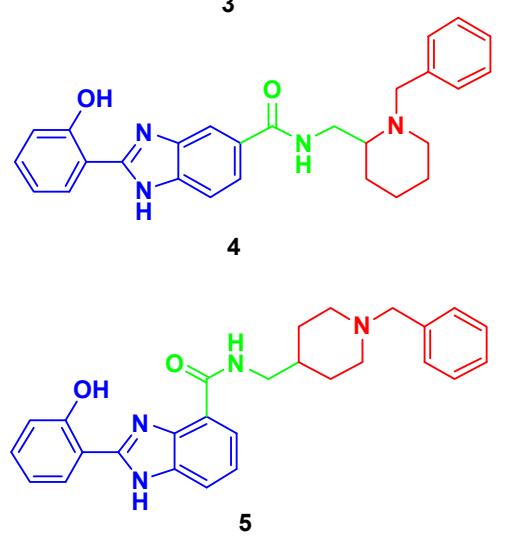

Figure 1. Structures of the studied donepezil-hydroxyphenylbenzimidazole (DNP-BIM) hybrids.

\section{Results and Discussion}

\subsection{Molecular Design and Docking}

Taking into account the recognized medical interest on the donepezil (DNP) drug to ameliorate AD symptoms, it was our inspiration to select $N$-benzylpiperidine and its isosteres benzylpiperazine and benzylpyridine as the main pharmacophores in the design and development of new hybrid compounds with multitarget capacity. The second pharmacophore herein explored is hydroxyphenylbenzimidazole (BIM), aimed to mimic the indanone scaffold of DNP, and also to provide metal-chelating and anti-A $\beta$ aggregation capacity, similarly to other hybrid analogues recently reported $[22,23]$. Thus, the $\mathrm{N}$-benzylpiperidine and its isostere moieties should account to the most important binding interaction of DNP within the catalytic anionic site (CAS) of AChE [10], while the BIM moiety should mimic the indanone moiety in DNP and reinforce the interaction with AChE through its extra-binding to the peripheral active site (PAS), thus enabling a dual binding mode.

Docking studies were performed with this set of new hybrids in order to gain some insight into the differences in their binding interactions with the active site of AChE. Specifically, it was intended to understand the effect of positional isomerization and of specific substitutions in the benzylpiperidine, benzylpiperazine, and hydroxyphenylbenzimidazole (BIM) moieties on the ligand-enzyme binding, namely in the dual binding mode. Similarly, as previously reported for compounds $\mathbf{1}$ and $\mathbf{2}$, the docking simulations of this set of hybrids were performed with AChE (PDB code: 1EVE) [24], using the X-ray crystal structure of the TcAChE complex with DNP. Firstly, the co-crystallized ligand (DNP) was docked back into the binding site of the enzyme and superimposed with the native ligand (Figure S1). Being satisfied with the good overlay, the same docking protocol was used for further docking studies with the target compounds. The best docked poses of each synthesized compound were selected and superimposed with that of DNP, as shown in Figure 2. Similar to the already published simple analogues $(\mathbf{1}, \mathbf{2})$, they showed a pattern of orientation resembling that of DNP. In particular, all the compounds have the first pharmacophore moieties, namely the benzyl-piperidinium (3-6), -piperazinium (7-11), or -pyridinium (12), anchored to the CAS of AChE (bottom of the gorge), through binding interactions via aromatic $\pi-\pi$ stacking with the phenyl ring from $\operatorname{Trp} 84 \mathrm{~A}$; at the middle of the gorge, the charged nitrogen atom can establish a cation $-\pi$ binding interaction with the phenyl group of Phe330. Noteworthy is the observation that the benzyl-piperidinium moieties of positional isomers (3-5) present some bending relative to that of DNP, though no significant effect appeared on the 
complexes with the benzyl-piperazinium substituted $(\mathbf{1 0}, \mathbf{1 1})$ or the benzyl-pyridinium $(\mathbf{1 2})$ moieties. Regarding the BIM moieties, similar to the DNP indanone ring, these moieties are at the entrance of the gorge interacting via $\pi-\pi$ stacking with the peripheral anionic residue Trp279. However, these docking simulations indicate for the BIM moieties less favorable interactions with PAS than DNP, which can be mainly attributed to the fact that the tricyclic BIM moieties are longer than the bicyclic indanone moiety of DNP. Furthermore, some additional distortion seems to occur for positional isomers (3-5) and substitution with big size substituents $\left(-\mathrm{NO}_{2}, 7 ;-\mathrm{OMe}, 9\right)$. In fact, the AChE inhibition assays herein performed (see Section 2.4.1) confirm lower inhibitory activity for 4, 5, 7, and 11, probably due to the existence of distorted configurations of these compounds inside the active site of the enzyme. Interestingly, the substitution by the small size fluorine atom $(\mathbf{8}, \mathbf{1 0})$ does not seem to contribute to any further distortion, as compared with the simple analogues $(\mathbf{1}, \mathbf{2})$, though from the docking studies we cannot observe any engaged positive binding interactions.

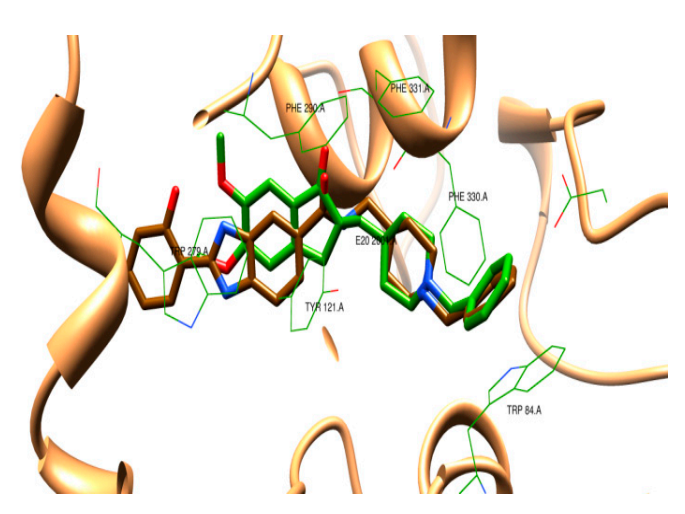

1

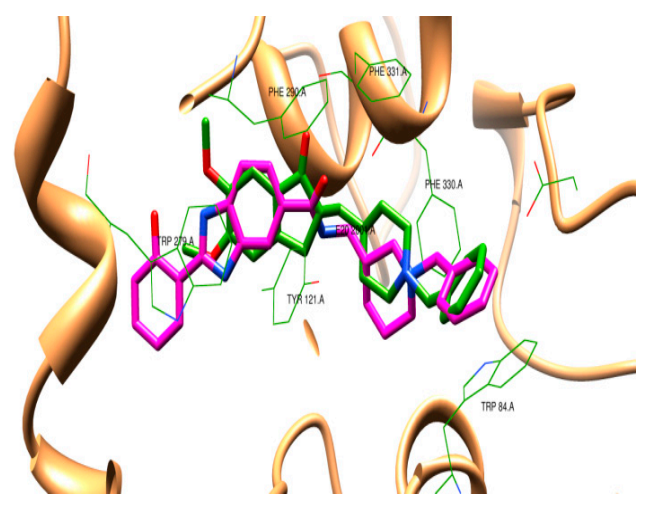

3

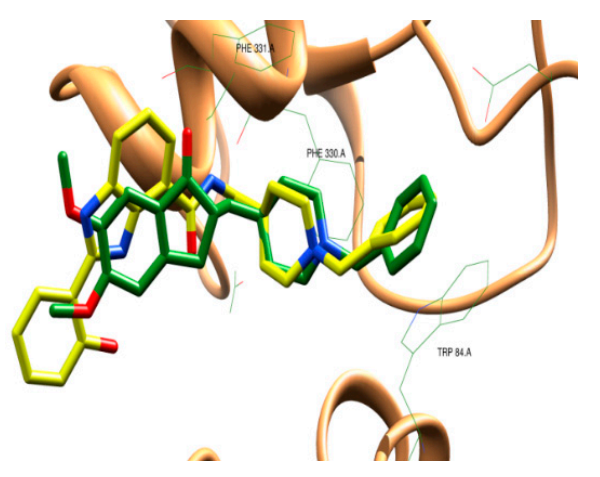

5

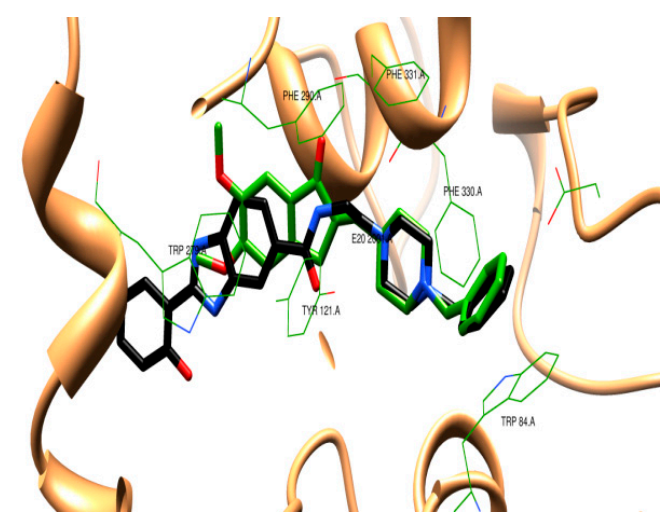

2
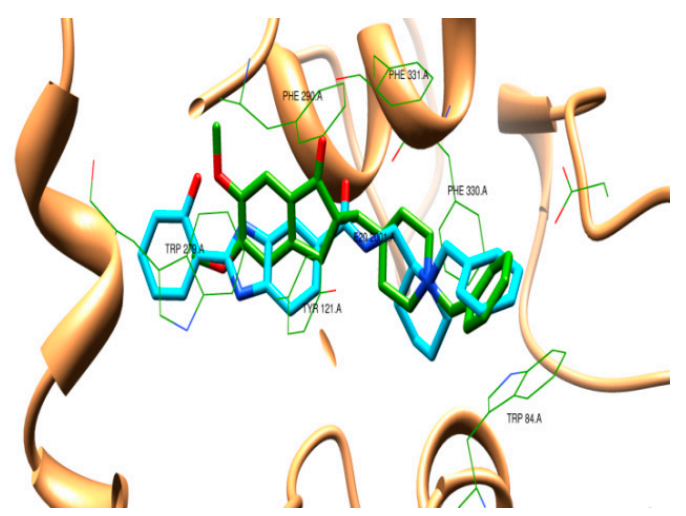

4

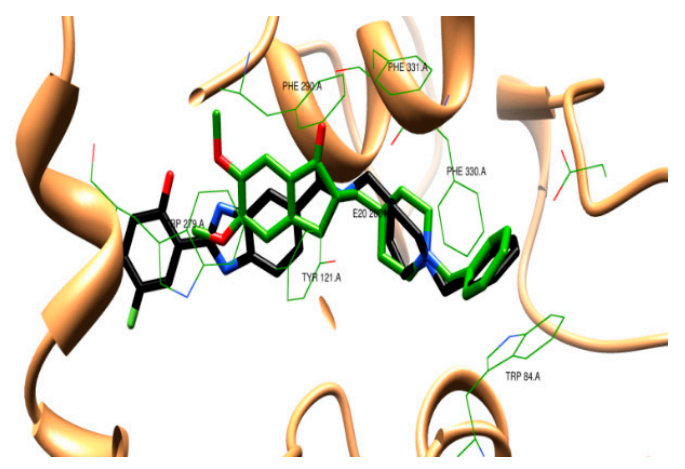

6

Figure 2. Cont. 


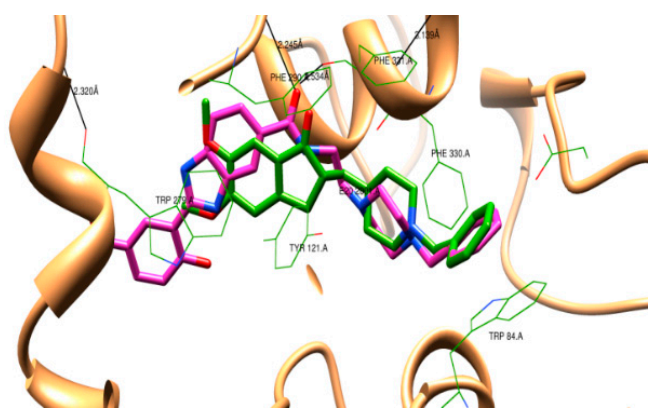

7

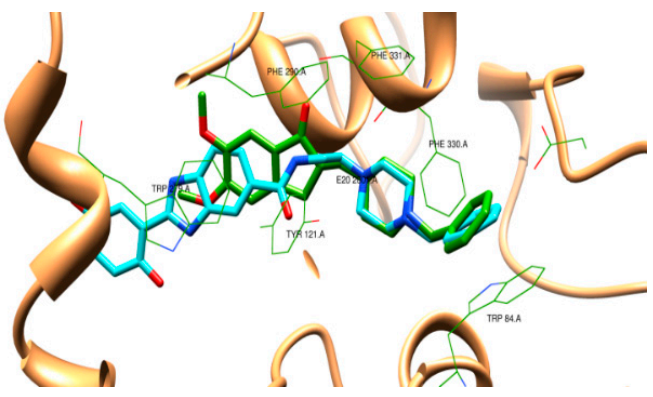

9

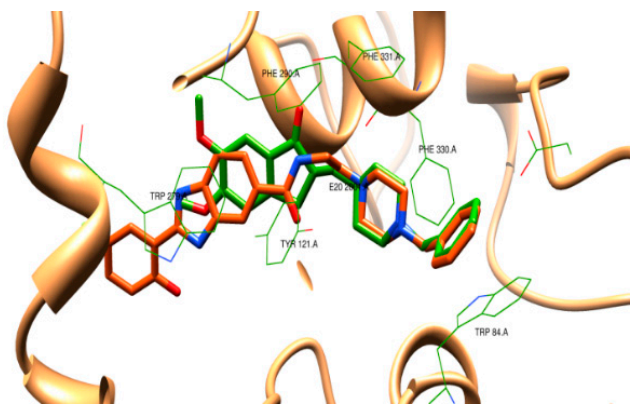

8

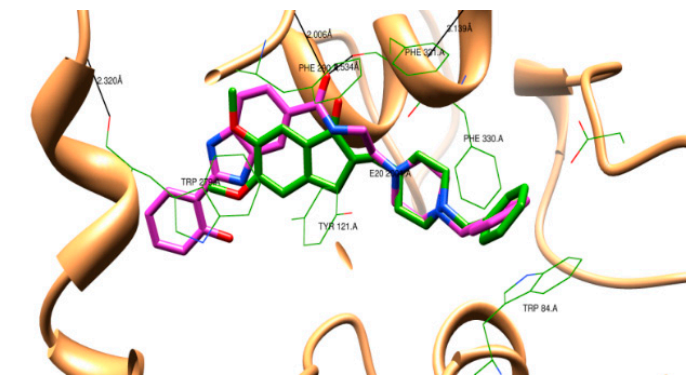

10

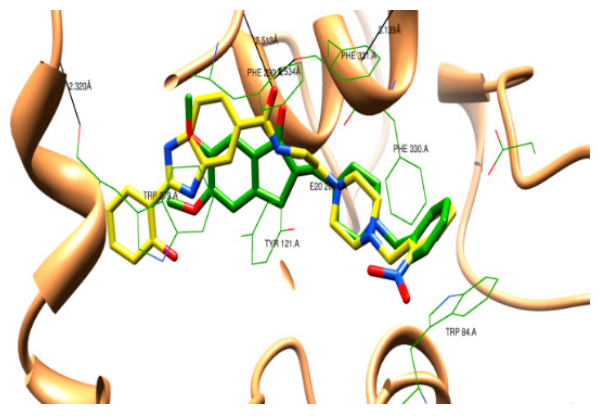

11

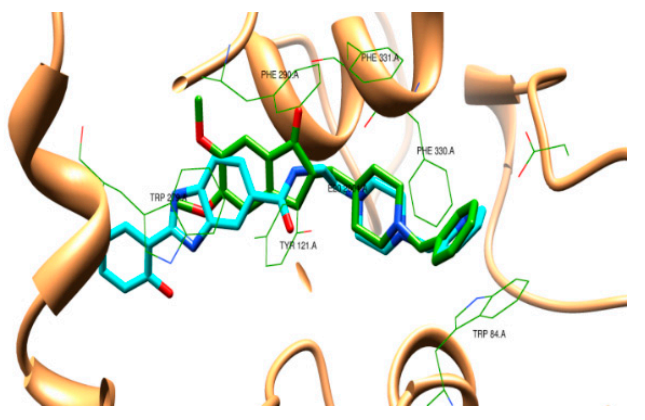

12

Figure 2. Superimposition of the different DNP-BIM hybrids and the original ligand (donepezil-green), as a result of their docking inside the acetylcholinesterase (AChE) active site (PDB code 1EVE) [24].

\subsection{Synthesis}

Twelve hybrid compounds resulted from the conjugation of a hydroxyphenylbenzimidazole (BIM) moiety with benzylpiperidine (PP, 1, 3-6), benzylpiperazine (PZ, 2, 7-11), and also benzylpyridine (12). The hybrids were obtained by following the convergent synthetic approach depicted in Scheme 1. The preparation of each final intermediate moiety, $\mathbf{b}$-series of benzyl amine derivatives (1-4b and 10-12b) and $c$-series of carboxyl BIM derivatives (1c, 5-9c), involved mostly procedures previously reported [22,23]. More specifically, the synthesis of the benzyl-cyclic amino derivatives ( $\boldsymbol{b}$-series) involved a first one-pot-two-step reaction, with preliminary protection of the primary alkylamine group to a phthalimide group by its reaction with phthalic anhydride (FA) in absence of solvent and subsequent benzylation of the secondary cyclic amine with benzyl bromide in dry acetonitrile under basic conditions; the final deprotection of the primary amine was performed with hydrazine hydrate in refluxing ethanol. The preparation of the $c$-series of intermediates, hydroxyphenylbenzimidazole acid derivatives, involved the cyclization of diaminobenzoic acid derivatives with diverse salicylaldehydes, in the presence of sodium metabissulfite and $\mathrm{N}, \mathrm{N}$-dimethylacetamide (DMA) (method A) [22]. However, for some compounds $(\mathbf{6 c}, \mathbf{7 c}, \mathbf{9 c})$, an eutectic solvent mixture, choline chloride/glycerol ( $\mathrm{ChCl} / \mathrm{Gly})$, was used (method B) instead of DMA, with improved effectiveness [25]. The last reaction step involved the 
coupling of amine intermediate moieties ( $\boldsymbol{b}$-series) with carboxylic intermediate moieties ( $\boldsymbol{c}$-series), via amide formation, and it was carried out in dry DMF, using NHS and DCC as activators.

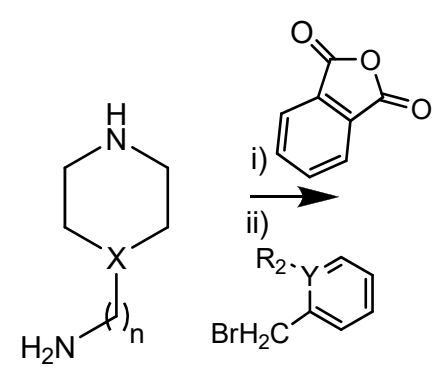

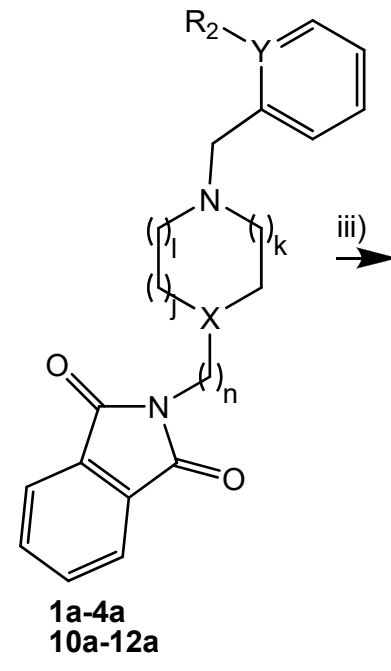

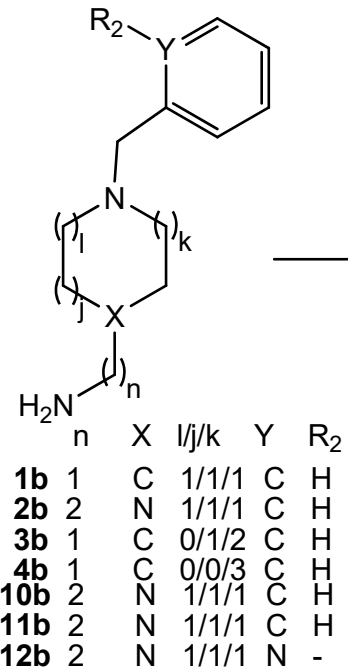<smiles>[R]c1cccc(C=O)c1O</smiles>
$\mathrm{R}_{1}$ $5-\mathrm{F}$ $5-\mathrm{NO}_{2}$ 4- $\mathrm{OCH}_{3}$

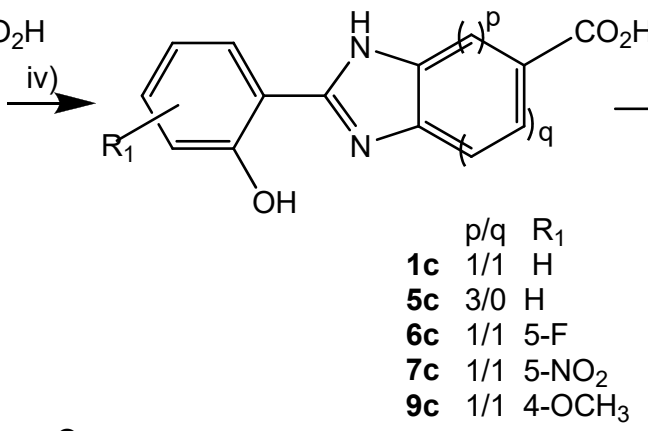

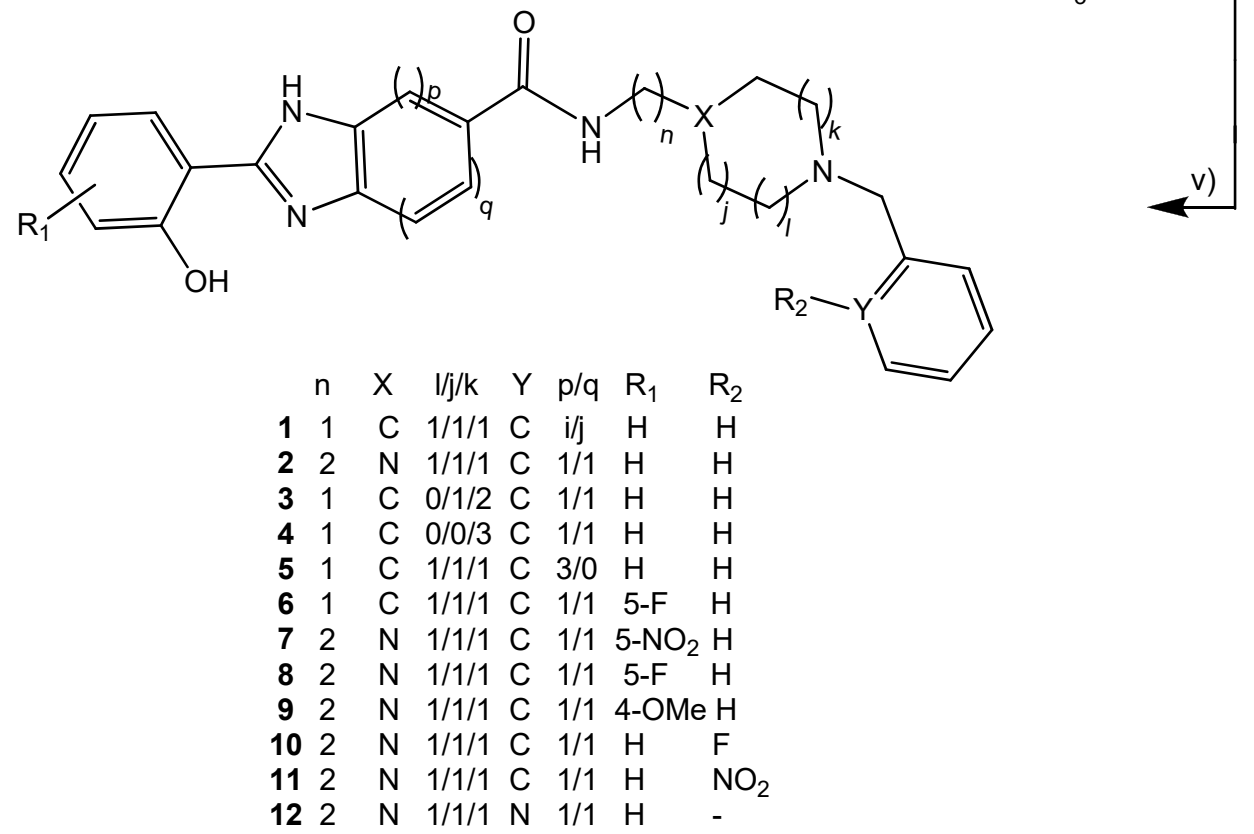

Scheme 1. Reagents and conditions: (i) Phthalic anhydride, net, $180{ }^{\circ} \mathrm{C}, 4 \mathrm{~h}$; (ii), TEA, $\mathrm{K}_{2} \mathrm{CO}_{3}, \mathrm{ACN}$, $50{ }^{\circ} \mathrm{C}, 3 \mathrm{~h}$; (iii) $\mathrm{N}_{2} \mathrm{H}_{4} \cdot \mathrm{xH}_{2} \mathrm{O}$; (iv) (A) $\mathrm{Na}_{2} \mathrm{~S}_{2} \mathrm{O}_{5}$, DMA, $100{ }^{\circ} \mathrm{C}, 12 \mathrm{~h}$; (B) $\mathrm{Na}_{2} \mathrm{~S}_{2} \mathrm{O}_{5}, \mathrm{ChCl} / \mathrm{Gly}, 50{ }^{\circ} \mathrm{C}, 30 \mathrm{~min}$; (v) DCC, N-hydroxysuccinimide, dry DMF, RT, $40 \mathrm{~h}$. 


\subsection{Metal Chelation}

In order to evaluate the chelating capacity of this type of compound towards $\mathrm{Cu}(\mathrm{II})$ and $\mathrm{Zn}$ (II), some of them (7 and 12) were selected and their acid-base behavior was firstly studied. A working medium of $50 \%(w / w)$ DMSO/water was chosen due to solubility reasons and also to enable the comparison with results for other hybrids, previously reported in the same medium. Although a $50 \% \mathrm{DMSO} /$ water $(w / w)$ medium has been implemented to perform these solution equilibrium assays, in terms of cellular studies the concentration of ligand employed is significantly lower $(<7 \mu \mathrm{M})$ and therefore the final concentration of DMSO used in culture media would be inferior $(<1 \%)$ and with no associated modifications in biological tissues.

The protonation constants of the compounds were determined by potentiometry (see Figure 3 and Table 1) by using Hyperquad [26].

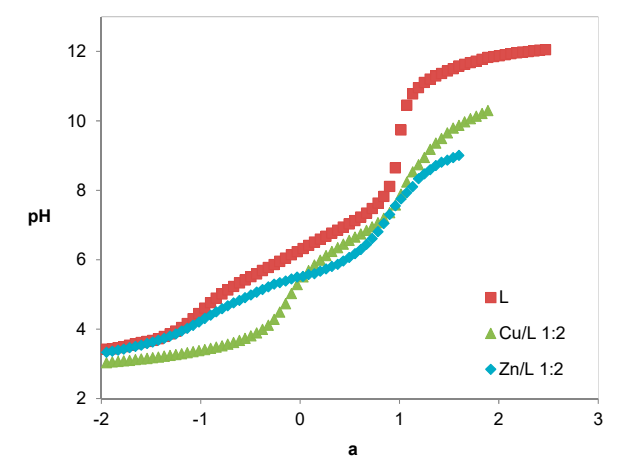

(A)

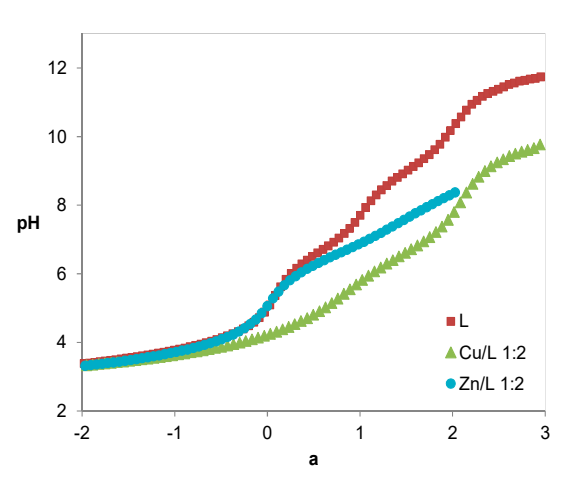

(B)

Figure 3. Potentiometric titration curves of compounds $7(A)$ and $12(B)\left(C_{L}=6.7 \times 10^{-4} \mathrm{M}\right.$, a represents moles of added base per mole of ligand). Experimental conditions: $50 \% w / w$ DMSO/water, $I=0.1 \mathrm{M} \mathrm{KCl}$, $T=25.0 \pm 0.1^{\circ} \mathrm{C}$.

Compound 7 was isolated in its neutral mono-protonated form (HL, a = 0 in Figure 3), although it has three dissociable protons $\left(\mathrm{H}_{3} \mathrm{~L}^{2+}\right)$, while compound 12 , with four dissociable protons $\left(\mathrm{H}_{4} \mathrm{~L}^{3+}\right)$, was isolated in its mono-positive charged di-protonated form $\left(\mathrm{H}_{2} \mathrm{~L}^{+}, \mathrm{a}=0\right.$ in Figure 3). Table 1 shows three values of protonation constants $\left(\log K_{i}=6.99,5.51\right.$, and 2.95) calculated for compound 7 and four values for compound $12\left(\log K_{i}=9.09,6.44,3.64\right.$, and 3.17).

${ }^{1} \mathrm{H}$ NMR titration studies previously reported revealed that, for compounds $\mathbf{1}$ and $\mathbf{2}$, the sequence of protonation corresponds to the following order: firstly, the phenolic oxygen of the BIM moiety, afterwards the $N$-piperazine nitrogen (opposite to benzyl group)/ $N$-piperidine nitrogen atom, and lastly the imidazole nitrogen $N(3)$ of the BIM moiety. Concerning compound 7, with analogous sequence of protonation, both $\log K_{1}$ (6.99) and $\log K_{2}$ (5.51) are much lower than the corresponding ones for compound 2 (see Table 1 ). The decrease of $\log K$ value corresponding to the phenolic oxygen is attributed to the resonance electron withdrawing nature of the nitro group present at the para position (e.g., phenol 9.98 [27] and 4-nitrophenol 7.15 [28]), that stabilizes the conjugated base. Regarding compound 12, the first two and the fourth protonation constants correspond to those of the analogous compound 2, while the third one $\left(\log K_{3}=3.64\right)$ is attributed to the pyridine nitrogen; the decrease of the $\log K$ value, when compared with that of pyridine (5.24, in water [29]), may be due to the electron withdrawing nature of the neighbor nitrogen atom from the piperazine moiety, that stabilizes the conjugated base by resonance effect. Finally, for all the hybrids contained in Table 1, the decreasing of the protonation constants corresponding to the $\mathrm{N}(3)$ atom $\left(\log K_{3}=2.86-3.37\right)$ and O-phenol $\left(\log K_{1}=6.99-9.09\right)$, when compared with equivalent standard groups (e.g., imidazole 6.95 [30] and phenol 9.98 [27]), reflects the existence of intramolecular hydrogen bond interactions involving these atoms in the BIM moiety. 
Table 1. Stepwise protonation constants ( $\log K_{\mathrm{i}}$ ) of compounds 7, 12 and other analogues for comparison purposes, as well as global formation constants ${ }^{\text {a }}$ for their $\mathrm{Cu}(\mathrm{II})$ and $\left.\mathrm{Zn}(\mathrm{II})\right)$ complexes $(T=25.0 \pm$ $0.1{ }^{\circ} \mathrm{C}, \mathrm{I}=0.1 \mathrm{M} \mathrm{KCl}, 50 \% w / w \mathrm{DMSO} /$ water) and $\mathrm{pM}^{\mathrm{b}}$ values.

\begin{tabular}{|c|c|c|c|c|}
\hline Compound & $\begin{array}{c}\mathbf{M}_{\mathbf{m}} \mathbf{H}_{\mathrm{h}} \mathrm{L}_{\mathbf{l}} \\
(\mathrm{mhl})\end{array}$ & $\log K_{i}$ & $\log \beta_{\mathrm{Cu}_{\mathrm{m}} \mathrm{H}_{\mathrm{h}} \mathrm{L}_{\mathrm{l}}}$ & $\log \beta_{\mathrm{Zn}_{\mathrm{m}} \mathrm{H}_{\mathrm{h}} \mathrm{L}_{\mathrm{l}}}$ \\
\hline 7 & $\begin{array}{c}(011) \\
(021) \\
(031) \\
(111) \\
(101) \\
(122) \\
(102) \\
(1-12) \\
\text { pM }\end{array}$ & $\begin{array}{l}6.99(2) \\
5.51(5) \\
2.95(6)\end{array}$ & $\begin{array}{c}14.23(5) \\
- \\
26.90(7) \\
15.27(8) \\
7.30(9) \\
10.9\end{array}$ & $\begin{array}{c}10.40(8) \\
4.98(8) \\
21.92(7) \\
10.22(8) \\
- \\
6.5\end{array}$ \\
\hline 12 & $\begin{array}{c}(011) \\
(021) \\
(031) \\
(041) \\
(111) \\
(101) \\
(102) \\
(1-12) \\
\text { pM }\end{array}$ & $\begin{array}{l}9.09(3) \\
6.44(4) \\
3.64(5) \\
3.17(6)\end{array}$ & $\begin{array}{c}16.26(3) \\
11.18(5) \\
17.14(7) \\
7.88(7) \\
10.4\end{array}$ & $\begin{array}{c}12.58(4) \\
6.26(5) \\
10.54(5) \\
2.07(7) \\
6.3\end{array}$ \\
\hline $1^{\mathrm{c}}$ & $\begin{array}{c}(011) \\
(021) \\
(031) \\
\mathbf{p M}\end{array}$ & $\begin{array}{l}8.671(1)^{c} \\
7.39(1)^{c} \\
3.21(1)^{c}\end{array}$ & $10.7 /$ & 6.3 \\
\hline $2^{c}$ & $\begin{array}{c}(011) \\
(021) \\
(031) \\
\text { pM }\end{array}$ & $\begin{array}{l}9.04(3) \\
6.76(6) \\
3.37(7)\end{array}$ & 10.7 & 6.3 \\
\hline $5^{\mathrm{d}}$ & $\begin{array}{c}(011) \\
(021) \\
(031) \\
\text { pM }\end{array}$ & $\begin{array}{l}8.98(2) \\
7.78(4) \\
2.86(5)\end{array}$ & 14.3 & 6.4 \\
\hline
\end{tabular}

Regarding compound 5 (see Table 1), previously studied [31], its three protonation constants and sequence of protonation were found to be similar to those of compound 1.

The metal chelating ability of hybrids 7 and 12, due to the BIM bidentate unity with $(N, O)$ coordination mode, was studied by potentiometry. Figure 3A,B show a change in the deprotonation profile of the ligand titration curves due to the presence of the metal ions. In fact, the curves for the $\mathrm{Cu}(\mathrm{II}) / \mathrm{L}$ systems lie well below that of the ligand, while for the $\mathrm{Zn}(\mathrm{II}) / \mathrm{L}$ systems stay under for a > -1 (compound 7) or a $>0$ (compound 12), thus supporting the formation of 1:1 and 1:2 M/L ratio complexes with the deprotonated and mono-protonated forms of the ligand and with relative metal dependent stability order $(\mathrm{Cu}>\mathrm{Zn})$. Table 1 contains the equilibrium models obtained from the fitting analysis of the potentiometric curves by program Hyperquad [26]. In these equilibrium models, which the coordination core of the compounds integrates the bidentate $(\mathrm{N}, \mathrm{O}) \mathrm{BIM}$ moiety, $\mathrm{MHL}$ and $\mathrm{MH}_{2} \mathrm{~L}_{2}$ 
correspond to species with the ligand containing one protonated nitrogen atom at the piperazine moiety, $\mathrm{ML}$ and $\mathrm{ML}_{2}$ correspond to complexes involving the completely deprotonated form of the ligand while $\mathrm{MH}_{-1} \mathrm{~L}_{2}$ are mixed ligand-hydroxo metal complexes.

Figure 4 shows the species distribution curves for the $1: 2 \mathrm{M}(\mathrm{II}) / \mathrm{L}(\mathrm{M}=\mathrm{Cu}, \mathrm{Zn})$ systems, involving compounds 7 and 12, by using the potentiometric determined model at the used experimental conditions.

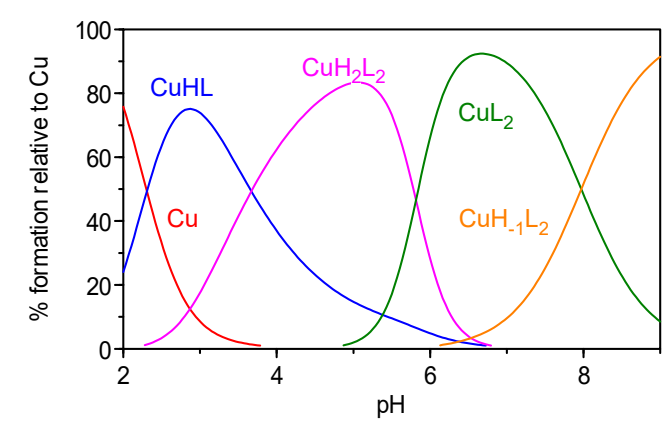

a)

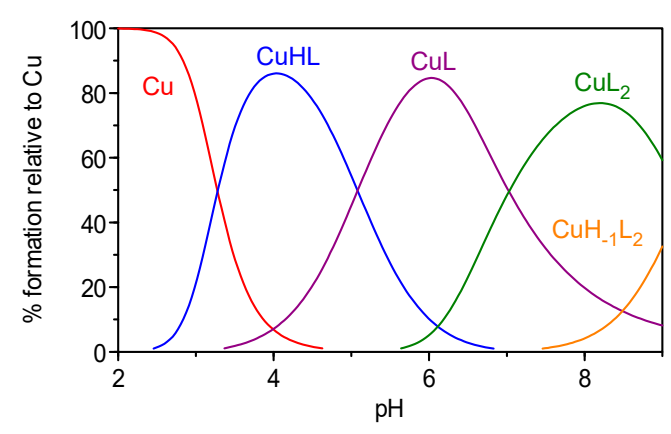

c)

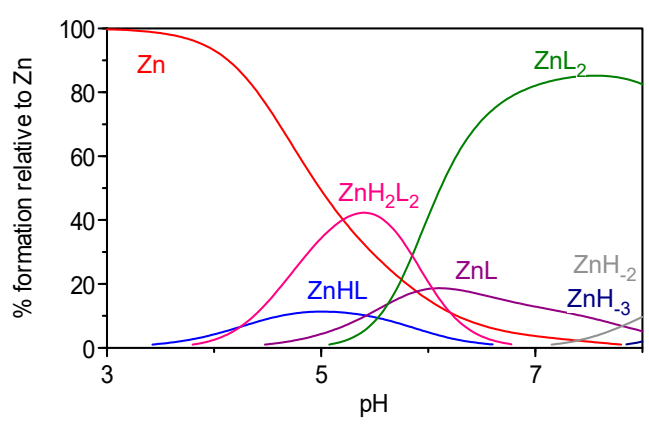

b)

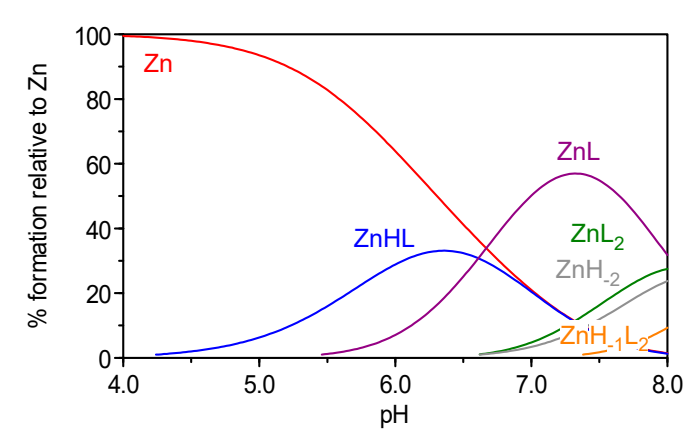

d)

Figure 4. Species distribution curves for the 1:2 $\mathrm{M}(\mathrm{II}) / \mathrm{L}$ systems with compound 7 and $\mathbf{a}) \mathrm{M}=\mathrm{Cu}, \mathbf{b}) \mathrm{M}$ $=\mathrm{Zn}$, as well as with compound 12 , and $\mathrm{c}) \mathrm{M}=\mathrm{Cu}, \mathrm{d}) \mathrm{M}=\mathrm{Zn}\left(\mathrm{C}_{\mathbf{L}}=6.7 \times 10^{-4} \mathrm{M}\right)$.

The species distribution curves show that, for the concentrations used in the experimental conditions, the metal complexation with compounds $\mathbf{7}$ and $\mathbf{1 2}$ starts at $\mathrm{pH}$ around 2 for $\mathrm{Cu}$ (II) or above 3.5-4 for $\mathrm{Zn}(\mathrm{II})$, with the formation of MHL species. Moreover, both 1:1 (MHL, ML) and 1:2 $\left(\mathrm{MH}_{2} \mathrm{~L}_{2}\right.$, $\left.\mathrm{ML}_{2}, \mathrm{MH}_{-1} \mathrm{~L}_{2}\right)$ species are formed and the mixed hydroxo-ligand complex $\left(\mathrm{MH}_{-1} \mathrm{~L}_{2}\right)$ starts to appear above $\mathrm{pH}$ 6-7. For the $\mathrm{Zn}(\mathrm{II}) / \mathrm{L}$ systems, some competition with metal hydroxide species occurs above $\mathrm{pH}$ 6.5-7. Previous results from UV-VIS spectral data collected for the analogous compounds $\mathbf{1}$ and $\mathbf{2}$ pointed towards a chelating core composed by the $N(3)$ imidazole and $O$-phenol atoms of the ligands, excluding the hypothesis of metal coordination through the distant nitrogen atoms of piperidine or piperazine [33]. Therefore, it is expectable that the same coordination core is kept for hybrids $\mathbf{7}$ and $\mathbf{1 2}$.

Comparison of the metal chelating capacity of compounds $\mathbf{7}$ and $\mathbf{1 2}$ with that of the already studied analogous DNP-BIM hybrids (see Table 1 ) reveals that these kind of ligands are good binders of $\mathrm{Cu}$ (II) and only moderate for $\mathrm{Zn}$ (II). In fact, the calculated $\mathrm{pM}$ values (at $\mathrm{pH} 7.4, C_{\mathrm{L}} / C_{\mathrm{M}}=10$, $\left.C_{\mathrm{M}}=10^{-6} \mathrm{M}\right)$ for the set of DNP-BIM hybrids studied are higher for $\mathrm{Cu}(\mathrm{II})(\mathrm{pCu}=10.4-14.3)$ than for zinc ( $\mathrm{pZn}=6.3-6.5$ ). Moreover, by comparing the $\mathrm{pM}$ values relative to 7 and 2 , it is possible to see some influence of the $p$-nitro group on the increase of stability of the metal complexes, although compound 7 has lower total basicity than 2 . Noteworthy is also the higher chelating capacity towards $\mathrm{Cu}(\mathrm{II})$ of compound $\mathbf{5}$ vs. $\mathbf{1}(\mathrm{pCu}(\mathbf{5})=14.3, \mathrm{pCu}(\mathbf{1})=10.7)$, attributable to the possibility of compound 5 being able to establish a tridentate $(\mathrm{N}, \mathrm{O}, \mathrm{O})$ coordination to the metal ion, by including the adjacent carbonyl oxygen atom [30], with correspondingly higher stability of its copper complex. 


\subsection{Biological Studies in Solution}

\subsubsection{Acetylcholinesterase (AChE) Inhibition}

The inhibition of AChE by the DNP-BIM hybrids herein studied was assayed by using a variation of Ellman's test $[23,34]$ and the IC $_{50}$ values obtained are included in Table 2. All the inhibitors, but the benzyl-pyridinium derivative (12), present $\mathrm{IC}_{50}$ values in low micromolar range. Among the piperidine (PP) series (PP-BIM), the best results were obtained with compounds 1, 3, and 6, while for the piperazine (PZ) series (PZ-BIM), the most potent were compounds 8, 9, and 10. Although the present hybrids are weaker AChE inhibitors than DNP $\left(\mathrm{IC}_{50}=0.026 \mu \mathrm{M}\right)$, this does not weaken the proposed drug design since the advantages of using a multi-target drug in multifactorial diseases can surpass the drawback of losing some specific property of a single-target drug.

Table 2. Summary of results obtained for inhibition of $A C h E$ and $\beta$-amyloid $(A \beta)$ aggregation of the DNP-BIM hybrids.

\begin{tabular}{|c|c|c|c|}
\hline \multirow[t]{2}{*}{ Compound } & \multirow{2}{*}{$\begin{array}{l}\text { TcAChE Inhibition a } \\
\operatorname{IC}_{50}(\mu \mathrm{M})\end{array}$} & \multicolumn{2}{|c|}{$\begin{array}{c}A \beta_{1-42} \text { Aggregation Inhibition } \\
(\%)\end{array}$} \\
\hline & & Self-Induced & Cu-Induced \\
\hline 1 & $4.2 \pm 0.8^{\mathrm{d}}$ & $48.8^{\mathrm{e}}$ & $69.0^{\mathrm{e}}$ \\
\hline 2 & $6.9 \pm 0.6^{\mathrm{d}}$ & $25.3^{d}$ & $37.7^{\mathrm{d}}$ \\
\hline 3 & $5.0 \pm 0.5$ & 71.4 & 81.8 \\
\hline 4 & $14 \pm 1$ & 47.6 & 55.9 \\
\hline 5 & $9 \pm 1^{\mathrm{e}}$ & $38.6^{\mathrm{e}}$ & $58.9^{e}$ \\
\hline 6 & $1.67 \pm 0.05$ & 51.2 & 61.0 \\
\hline 7 & $21 \pm 3$ & 57.6 & 71.4 \\
\hline 8 & $4.3 \pm 0.3$ & 50.6 & 55.2 \\
\hline 9 & $1.87 \pm 0.8$ & 43.7 & 66.0 \\
\hline 10 & $4.32 \pm 0.03$ & 39.1 & 75.8 \\
\hline 11 & $20 \pm 1$ & 22.7 & 43.5 \\
\hline 12 & $>10^{2}$ & 30.1 & 44.4 \\
\hline$D_{N P}^{f}$ & 0.026 & - & - \\
\hline
\end{tabular}

\footnotetext{
a The values are means of three independent experiments \pm SD; AChE from Electric eel. ${ }^{\mathrm{b}}$ Inhibition of self-mediated $\mathrm{A} \beta_{42}$ aggregation (\%) with or without copper $(40 \mu \mathrm{M})$. The thioflavin-T fluorescence method was used, and the measurements were carried out in the presence of an inhibitor $(40 \mu \mathrm{M}$ and $20 \mu \mathrm{M}$ for compound 4$) .{ }^{\mathrm{C}}$ The values are the means of three independent measurements in duplicate (SEM $<10 \%) .{ }^{d}$ Reference [31] (A $\beta$ aggregation inhibitory assays for $\left.C_{\text {inhibitor }}=80 \mu \mathrm{M}\right)$; ${ }^{\mathrm{e}}$ reference [31]; ${ }^{\mathrm{f}}$ reference [35].
}

In order to understand the effect of different structural changes on the inhibitory capacity of AChE such as the existence of positional isomers (compounds 1, 3, and 4) or the inclusion of $R_{1}$ or $R_{2}$ substituents, a brief structure-activity analysis can be performed based on graphical representation of the enzymatic activity ( $\mathrm{IC}_{50}$ ) (Figure 5).

Analysis of the data illustrated in Figure 5A (or Table 2), shows that the inhibitory capacity of the positional isomers on the PP moiety is according to the following sequential order: para (1) $>$ meta (3) > ortho (4). Concerning the attachment point in the BIM moiety, the para position (1) is also preferred to the ortho one (5). Therefore, apart from compounds 3, 4, and 5, this series of DNP-BIM hybrids is mainly composed by positional para isomers, both in the PP and in the BIM moieties, aimed to be better accommodated in the enzyme structure and so with higher inhibitory activity against AChE. Figure 5A also shows that the inclusion of a fluorine in the BIM moiety leads to an activity improvement e.g., 1 versus 6). 


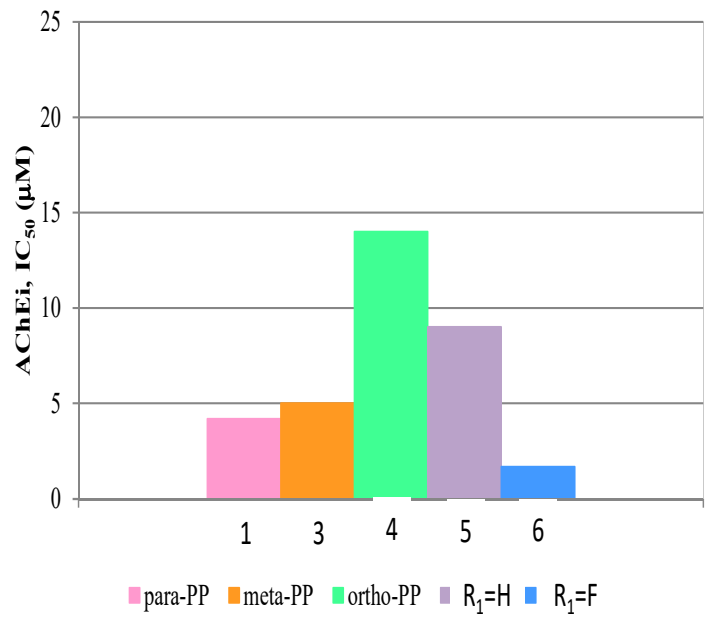

(A)

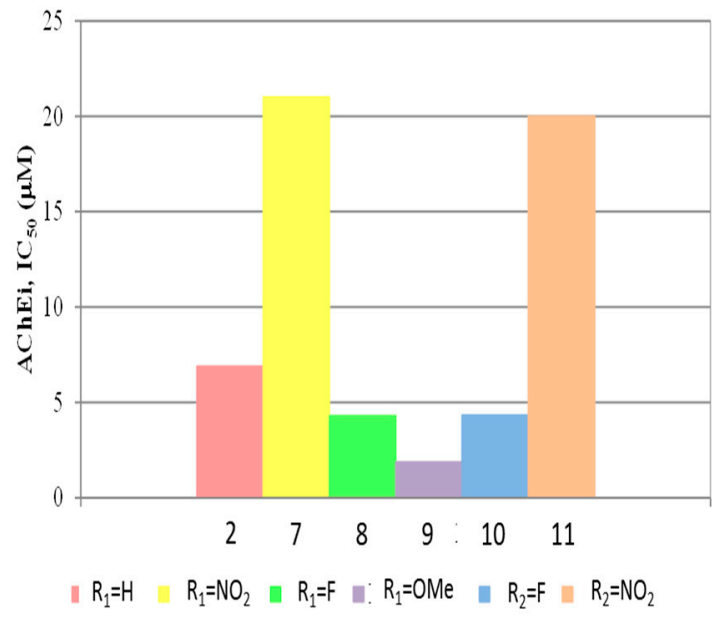

(B)

Figure 5. Graphical summary of the effect of different structural parameters on the inhibition of AChE (AChEi, $\mathrm{IC}_{50}$ ) for: (A) PP-BIM hybrids; (B) PZ-BIM hybrids.

On the other hand, Figure $5 \mathrm{~B}$ shows the effect of substituent groups, as $\mathrm{R}_{1}$ in the BIM moiety or $\mathrm{R}_{2}$ in the benzyl of the PZ unity. In both types of substitutions, it is evident that the fluorine (and also $\mathrm{R}_{1}=-\mathrm{OMe}$ ) leads to enhancement of the inhibitory capacity, while the nitro group decreases its value.

Overall, the best AChEi activity was achieved for para-/para-hybrids $\mathbf{6}$ and 9, with fluorine and methoxy $\mathrm{R}_{1}$ substituents in the BIM moiety, respectively, which demonstrates the determinant role of these substituents in the establishment of interactions within the active site of AChE.

\subsubsection{Inhibition of $A \beta_{1-42}$ Aggregation}

The anti-amyloidogenic capacity of the compounds was also evaluated in vitro, in the absence and presence of $\mathrm{Cu}(\mathrm{II})$, based on the measurement of the fluorescence emission of Thioflavin T (ThT), a stain known by its A $\beta$ fibril binding capacity $[36,37]$. This binding interaction can be analyzed by fluorimetry, since the presence of ThT-fibrils increases the absorbance and the emission of the ThT dye, and it also induces red shifts on the absorbance (from 385 to $446 \mathrm{~nm}$ ) and emission peaks (from 445 to $485 \mathrm{~nm})$ [22]. All the measurements were performed after incubation $\left(24 \mathrm{~h}, 37^{\circ} \mathrm{C}\right)$ of the self-mediated and $\mathrm{Cu}^{2+}$-induced $\mathrm{A} \beta$ aggregates in the presence/absence of the compounds under evaluation.

In fact, it is well known that $\mathrm{A} \beta$ binds $\mathrm{Cu}(\mathrm{II})$ and, although this interaction has been associated to the induction of $A \beta$ aggregation $[15,16]$, it has also been admitted that it can lead to the precipitation of amorphous deposits of the peptide and not to ThT-positive $\beta$ sheet rich amyloid fibril formation with different studies being performed on the analysis of the effect of $\mathrm{Cu}(\mathrm{II})$ on the propensity for $\mathrm{A} \beta$ fibril formation as well as on the effect of metal chelators on this process [38,39]. Several reported fluorescence studies based on the ThT dye have been performed in different experimental conditions (solvent used for $\mathrm{A} \beta, \mathrm{pH}$, and incubation time), which turn difficult comparison of results. Under our experimental method it was observed a tendency for decreasing the fluorescence intensity for $A \beta$ in the presence of copper, in comparison with its absence, which may be due to some precipitation of amorphous deposits of the peptide rather than formation of $\beta$ sheets [38,39]. In former studies, with TAC-BIM derivatives (1, 2) [22,23,33], a fluorescence-independent method like transmission electron microscopy (TEM) was used, due to possible quenching interferences in the emission of the paramagnetic copper ion, and it was observed that scarcer aggregates appear in the presence of $\mathrm{Cu}$ (II) when comparing $A \beta$ with $A \beta+C u(I I)$. Furthermore, it has been proposed that metal chelators might either dissolve the deposits in the brain tissue or prevent $A \beta$ aggregation.

Herein, due to solubility problems of some compounds in the phosphate buffer $(0.215 \mathrm{M}, \mathrm{pH} 8.0)$ of the working medium, the assays were carried out in the presence of $40 \mu \mathrm{M}$ concentration of 
inhibitor and $20 \mu \mathrm{M}$ in the case of compound 4, instead of $80 \mu \mathrm{M}$ as previously reported [33]. The obtained data, expressed as percentage of aggregation inhibition, is included in Table 2 and graphically presented in Figure 6. The results show that all the compounds are able to inhibit A $\beta$ aggregation with good-to-moderate activity. The activity dependence on ligand structural features may be mainly explained by the different ability for intercalation into the fibrils, as already assumed for other inhibitors [22,40]. Among the hybrids under study, 3 exhibited the highest inhibitory activity for selfand $\mathrm{Cu}$-induced $A \beta$ aggregation, although very good inhibitory activity is also presented by 1,6 , and 7. The data obtained for compounds 6 and 7 indicate that the presence of $\mathrm{R}_{1}=\mathrm{F},-\mathrm{NO}_{2}$ substituents in the BIM have some small positive effect on the inhibition of $A \beta$ aggregation. On the other hand, compounds 5, 10, 11, and 12 showed decreased inhibitory activity, which may result from a somehow more difficult intercalation into the fibrils, when there is an ortho-attached BIM or when the PZ benzyl unity is substituted.

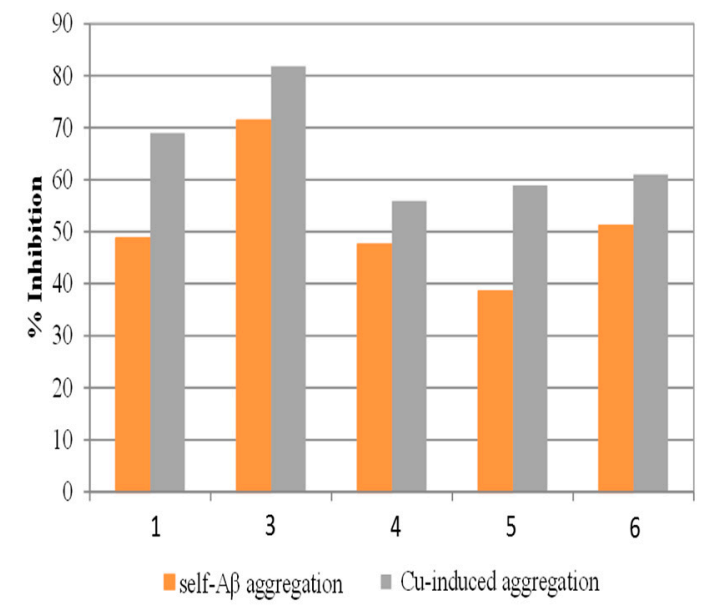

(A)

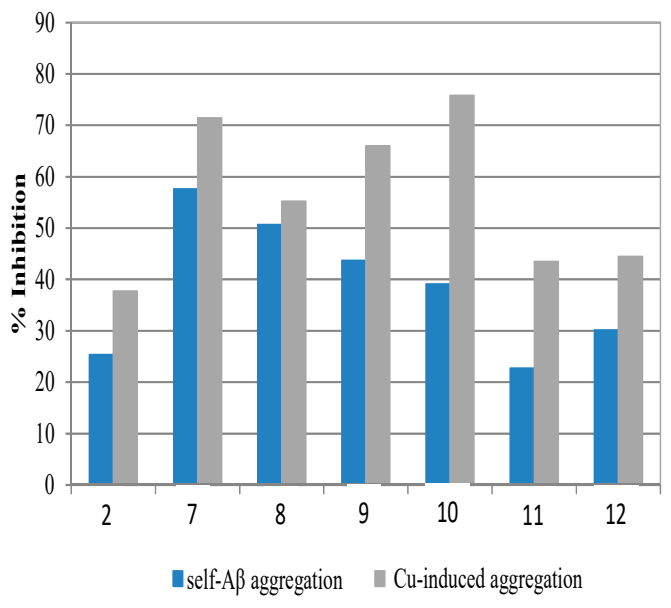

(B)

Figure 6. Graphical summary of the effect of structural parameters on the inhibition of $A \beta$ aggregation (self- and Cu-induced, in \%) for: (A) PP-BIM hybrids; (B) PZ-BIM hybrids.

Concerning the inhibition of $\mathrm{Cu}$-induced $\mathrm{A} \beta$ aggregation, all the compounds induce an increase when comparing with their corresponding capacity for self-inhibition, in accordance with their good chelating capacity towards copper. Nevertheless, these chelators have conditional dissociation constants $\left(K_{\mathrm{d}}^{\prime}\right)$ for the copper complexes at pH 7.4 of 34 nanomolar $(\mathbf{1}), 24$ nanomolar $(\mathbf{2}), 254$ picomolar (5), 80 nanomolar (7), and 365 picomolar (12). These values are outside the proposed range $K_{d}^{\prime}=1-10$ picomolar corresponding to chelators eventually able to retrieve copper from $\mathrm{A} \beta$ peptide $\left(K_{\mathrm{d}}^{\prime}=10\right.$ picomolar-100 nanomolar for $\mathrm{Cu}(\mathrm{A} \beta)$ complexes) [41]. Therefore, it seems that there is no competition for copper between these BIM hybrids and $A \beta$ peptide, and so the inhibition process must be mainly due to ligand intercalation between the $\beta$-sheets of $A \beta$ fibrils. TEM assays previously performed by us on analogous BIM hybrids $[22,23,33]$ also confirmed the role of these kinds of compounds in the reduction of $A \beta$ aggregation, both in the absence and presence of copper.

\subsection{Cell Viability and Neuroprotection}

The neuroprotective effect of DNP-BIM hybrids designed for AD was evaluated using SH-SY5Y cell line treated with $\mathrm{A} \beta_{1-42}$ or ferrous sulfate and L-Ascorbic acid (Fe/Asc). A dose-response curve was performed to select a non-toxic concentration of each compound (Figure 7). For all the compounds, a concentration of $2.5 \mu \mathrm{M}$ showed to be the highest non-toxic value.

Extracellular formation of senile plaques of aggregated $A \beta$ along with the production of reactive oxygen species (ROS) are processes involved in the neurodegeneration that characterize AD [42]. 
Herein, we observed that $A \beta$ induces a decrease in cell viability close to $50 \%$ and, remarkably, compounds 9 and $\mathbf{1 0}$ prevented A $\beta$-induced cell toxicity (Figure 8). Additionally, ROS production is also one of the hallmarks associated with AD pathogenesis [42]. To study the neuroprotective effect of DNP-BIM hybrids against oxidative stress, we incubated our cell model with Fe/Asc, which showed a decrease of $25 \%$ in the cell viability when compared with untreated cells (Figure 9). However, none of the compounds presented a statistically significant neuroprotective effect by preventing ROS production, even the compounds $\mathbf{9}$ and $\mathbf{1 0}$ that showed to be able to inhibit $\mathrm{A} \beta$ aggregation.

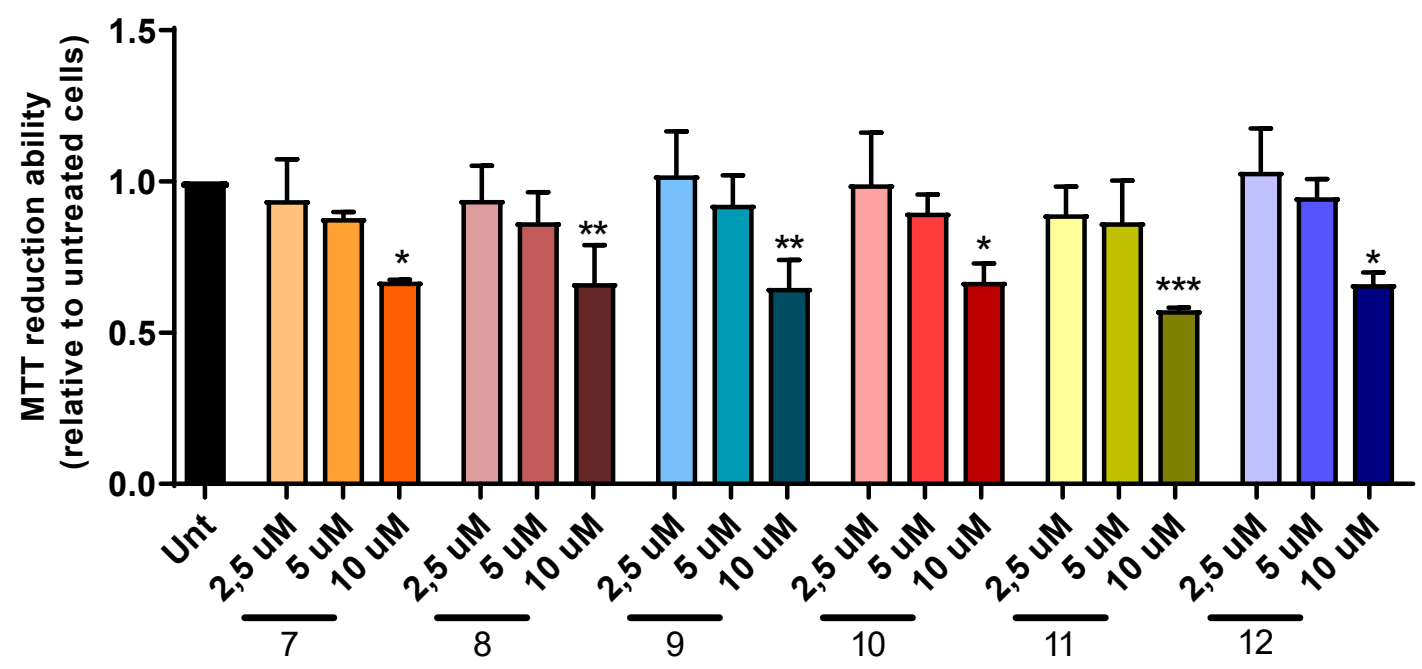

Figure 7. Dose-response screening to select non-toxic concentrations of compounds 7-12. Cells were treated with different concentrations of the compounds for $24 \mathrm{~h}$ and MTT reduction assay was performed to evaluate cell viability. Results are expressed relatively to SH-SY5Y untreated cells, with the mean \pm standard error of the mean (SEM) derived from four different experiments. ${ }^{*} p<0.05$; ${ }^{* *} p<0.01 ;{ }^{* *} p<0.001$, significantly different when compared with SH-SY5Y untreated cells.

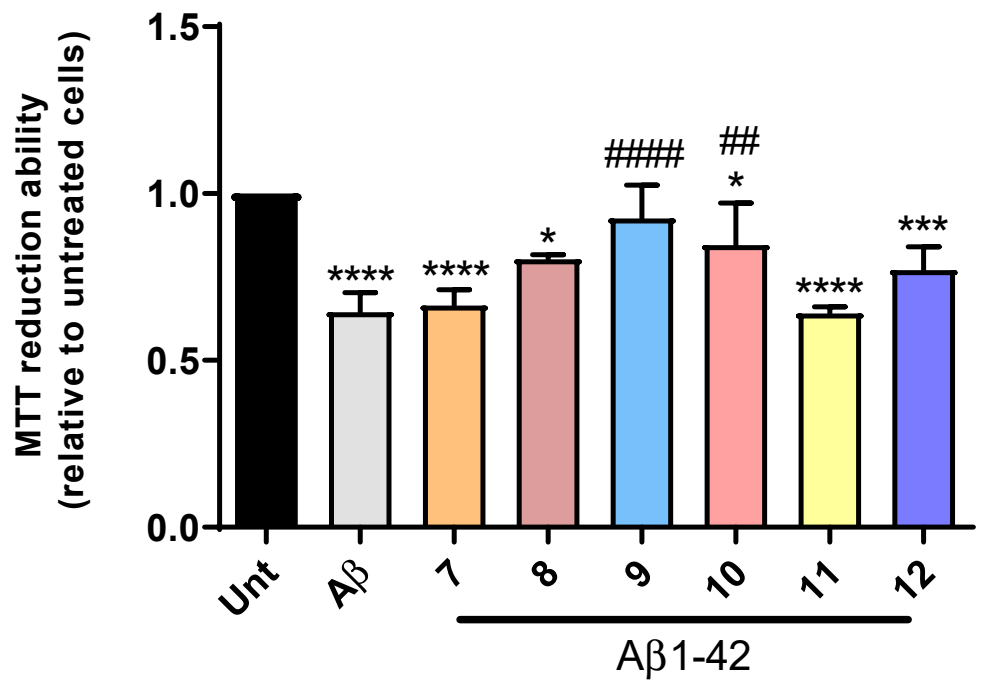

Figure 8. Neuroprotective effect of compounds 7-12 from A $\beta_{42}$-induced toxicity on SH-SY5Y cells. Cells were treated with $A \beta_{42}$ peptide $(1 \mu \mathrm{M})$ for $24 \mathrm{~h}$ in the presence or absence of the compounds $(1 \mathrm{~h}$ pre-incubation plus $24 \mathrm{~h}$ co-incubation). Evaluation of cell viability was performed using the MTT reduction assay. Results are expressed relatively to SH-SY5Y untreated cells, with the mean \pm SEM derived from four different experiments. ${ }^{*} p<0.05 ;{ }^{* * *} p<0.001 ;{ }^{* * * *} p<0.0001$, significantly different when compared with SH-SY5Y untreated cells; \#\# $p<0.01$; \#\#\#\# $p<0.0001$, significantly different when compared with $\mathrm{A} \beta_{42}$ treated SH-SY5Y cells. The concentration used for all the compounds was $2.5 \mu \mathrm{M}$. 


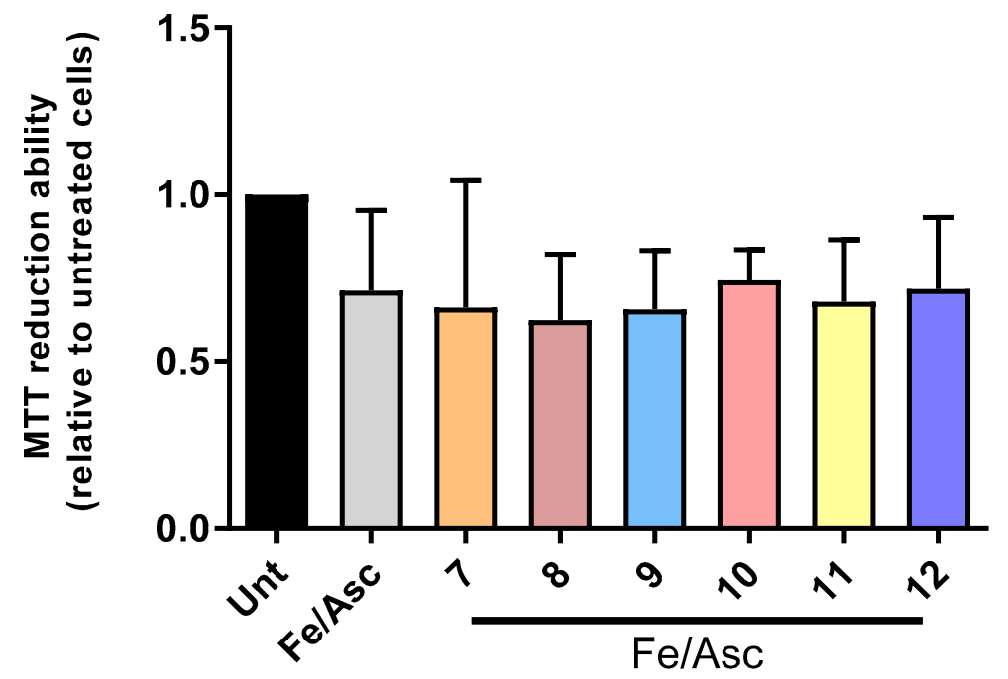

Figure 9. Neuroprotective effect of compounds 7-12 from $L$-Ascorbic Acid (AscH (-))/Ferrous sulphate (Fe) toxicity on SH-SY5Y cells. Cells were treated with Fe/Asc (2.5 mM and $5 \mathrm{mM}$, respectively) for $24 \mathrm{~h}$ in the absence or in the presence of the compounds ( $1 \mathrm{~h}$ pre-incubation plus $24 \mathrm{~h}$ co-incubation). Evaluation of cell viability was performed using the MTT reduction assay. Results are expressed relative to SH-SY5Y untreated cells, with the mean \pm SEM derived from four different experiments. The concentration used for all the compounds was $2.5 \mu \mathrm{M}$.

\subsection{Prediction of Pharmacokinetic Properties}

To get some insight on the drug-likeness of the studied hybrid compounds, in silico calculations of some pharmacokinetic descriptors were performed by the QikProp program [43]. Analysis of the selection of calculated parameters depicted in Table 3 shows that almost all the compounds present no violations of Lipinski's rule of five [44], which can be indicative of their potential oral-bioavailability. However, compounds 7 and 11, with a nitro substituent, present a molecular weight (MW) slightly higher than $500 \mathrm{Da}$ (516.55 and 500.55), resulting in one violation of that rule. The range of values (2.586-4.513) calculated for $\log P$ ( $c \log P$, octanol-water partition coefficient) are within the normal range of values calculated for drugs ( -2 to 6.5 ) [43], although hydrophilic character is generally higher for the piperazinic derivatives $(X=N)$, as compared with the piperidinic analogues $(X=C)$. To assess the capacity of the compound to cross the blood-brain barrier (BBB), log BB was calculated. The range of values obtained for $\log B B$ are also within the range calculated for drugs ( -3 to 1.2) [43], although it is generally accepted that compounds with $\log \mathrm{BB}<-1$ are poorly distributed in the brain and so with low CNS activity. Regarding the Caco-2 permeability, the values obtained for the piperidinic derivatives are higher than for the piperazinic analogues $(<100)$, thus indicating for this last series of compounds a more moderate absorption from the intestinal tract to the blood. Overall, the remarkably low values obtained for Caco-2 permeability of the nitro-derivatives $(<10)$, together with the lowest values for $c \log P$ and $\log \mathrm{BB}$, suggest that these hybrids should be excluded from further drug development.

Overall, excepting the nitro-derivatives, generally, this set of hybrids presents well balanced lipophilic/hydrophilic character and moderate blood-brain barrier permeability (log BB), thus making them eligible as potential drug candidates. 
Table 3. Pharmacokinetic properties of the compounds as predicted in silico by software QikProp v.2.5 [43].

\begin{tabular}{ccccccc}
\hline Comp. & $\begin{array}{c}\text { MW } \\
\text { (Da) }\end{array}$ & clog $\boldsymbol{P}$ & $\log$ BB & $\begin{array}{c}\text { Caco-2 Permeability } \\
\text { (nm/s) }\end{array}$ & CNS & $\begin{array}{c}\text { Violations of } \\
\text { Lipinski's Rule }\end{array}$ \\
\hline 1 & 440.54 & 4.386 & -0.730 & 194 & - & 0 \\
2 & 455.55 & 2.587 & -0.097 & 48 & $+/-$ & 0 \\
3 & 440.54 & 4.122 & -0.825 & 155 & - & 0 \\
4 & 440.54 & 4.202 & -0.981 & 121 & - & 0 \\
5 & 440.54 & 4.352 & -0.638 & 225 & $+/-$ & 0 \\
6 & 458.53 & 4.513 & -0.663 & 177 & $+/-$ & 0 \\
7 & 516.55 & 2.421 & -1.148 & 7 & - & 1 \\
8 & 473.54 & 3.490 & -0.147 & 61 & - & 0 \\
9 & 485.58 & 2.840 & -0.029 & 79 & $+/-$ & 0 \\
10 & 473.54 & $3.455-$ & -0.385 & 45 & - & 0 \\
11 & 500.55 & 2.604 & -1.641 & 6 & $+/-$ & 0 \\
12 & 456.54 & 2.686 & -0.597 & 34 & + & 0 \\
DNP & 379.50 & 4.269 & 0.132 & 893 & \\
\hline
\end{tabular}

\section{Materials and Methods}

\subsection{Chemicals}

For the synthesis, all the reagents (from Sigma-Aldrich, St. Louis, MO, USA, Alfa-Aesar, Kandel, Germany, Acros, Thermo Fisher Scientific, Geel, Belgium) were of analytical grade and used as supplied. Whenever necessary, the solvents were dried according to standard methods [45]. The chemical reactions were followed by thin layer chromatography (TLC) using alumina plates coated with silica gel 60 F254 (Macherey-Nagel, Düren, Germany). Column chromatography purifications were performed on silica gel (Merck 230-400 mesh (Geduran Si 60Darmstadt, Germany). The purity of the compounds was assessed by determination of the melting points (M.P.) and by using NMR and mass spectral techniques. The melting points were measured with a Leica Galen III (Microsystems, Wetzlar, Germany) hot stage apparatus and are uncorrected. ${ }^{1} \mathrm{H}$ - and ${ }^{13} \mathrm{C}-\mathrm{NMR}$ spectra were recorded either on Bruker AVANCE III-300 (300 MHz and 75.5 MHz) or Bruker AVANCE III-400 (400 MHz and $100 \mathrm{MHz}$ ) NMR spectrometers (Billerica, MA, USA), at $25^{\circ} \mathrm{C}$. Chemical shifts are reported as $\delta$ values (ppm) from internal reference TMS (tetramethylsilane, Sigma-Aldrich, St. Louis, MO, USA) and coupling constants $(J)$ in Hertz. The following abbreviations have been used: $s=$ singlet, $d=$ doublet, $\mathrm{t}=$ triplet, $\mathrm{m}=$ multiplet. The mass spectra were performed on a $500 \mathrm{MS}$ LC Ion Trap mass spectrometer (Varian Inc., Palo Alto, CA, USA) equipped with an ESI ion source, operated in the positive ion mode.

\subsection{Synthesis of the Compounds}

3.2.1. Synthesis of the Benzyl-Piperidine as Well as Benzyl- and Pyridinyl-Piperazine Alkylamino Derivatives (1-4b,10-12b)

3.2.1.1. Synthesis of the $N$-benzyl Compounds with Isoindoline-1,3-Dione Protection (1-4a, 10-12a)

General Procedure

Phthalic acid anhydride (1 eq) and the aminoalkyl-piperidines or -piperazine derivatives (i-(aminomethyl)piperidine $(\mathrm{i}=2,3,4)$ or 1 -(2-aminoethyl)piperazine $(1 \mathrm{eq})$ were heated at $160{ }^{\circ} \mathrm{C}$ for $4 \mathrm{~h}$. The resulting dark brown solid (1 eq) was mixed with $\mathrm{K}_{2} \mathrm{CO}_{3}(6.6 \mathrm{eq})$, triethylamine (1.4 eq), and benzyl bromide derivatives or 2-(bromomethylpyridine ( $2.3 \mathrm{eq})$, and refluxed in acetonitrile for $24 \mathrm{~h}$. Then, the mixture was cooled at rt, filtered and to the organic phase was added water, and then extracted with ethyl acetate (three times). The organic layers were collected, dried over anhydrous sodium sulphate, 
and concentrated under reduced pressure. The crude material was purified through chromatography column (with eluent: DCM/MeOH/TEA (98:2:0.1) or $\mathrm{ACN} / \mathrm{H}_{2} \mathrm{O}(7: 1)$ ) or recrystallization.

2-((1-Benzylpiperidine-4-yl)methyl)isoindoline-1,3-dione (1a). Starting from 4-(aminomethyl)piperidine and afterwards benzyl bromide the a pure title compound was obtained as a yellow solid $(\eta=40 \%)$, M.P. $\left.=129-132{ }^{\circ} \mathrm{C}\right) .{ }^{1} \mathrm{H}$ RMN $\left(300 \mathrm{MHz}, \mathrm{DMSO}-d_{6}\right), \delta(\mathrm{ppm}): 1.24-1.38,1.52-1.91,3.44-3.50(\mathrm{~m}, 9 \mathrm{H}$, piperidine), $2.73\left(\mathrm{~d}, 2 \mathrm{H}, J=12.0 \mathrm{~Hz}, \mathrm{NCH}_{2} \mathrm{CH}\right), 3.41\left(\mathrm{~s}, 2 \mathrm{H}, \mathrm{NCH}_{2} \mathrm{Ph}\right), 7.15-7.40(\mathrm{~m}, 5 \mathrm{H}, \mathrm{Ph}), 7.79-7.91$ (m, 4H, PhTh). M/z (ESI-MS): $335(\mathrm{M}+1)^{+}$.

2-(2-(4-Benzylpiperazin-1-yl)ethyl)isoindoline-1,3-dione (2a). Starting from 1-(2-aminoethyl)piperazine, the crude product was washed with diethylether affording the pure title compound as a yellow solid $(\eta=35 \%) .{ }^{1} \mathrm{H}$ NMR $\left(300 \mathrm{MHz}, \mathrm{MeOD}-d_{4}\right), \delta(\mathrm{ppm}): 2.384-2.640(\mathrm{~m}, 8 \mathrm{H}$, piperazine), $2.675(\mathrm{t}, 2 \mathrm{H}$, $\left.J=6.0 \mathrm{~Hz}, \mathrm{PhthCH}_{2} \mathrm{CH}_{2} \mathrm{~N}\right), 3.52\left(\mathrm{~s}, 2 \mathrm{H}, \mathrm{NCH}_{2} \mathrm{Ph}\right) 3.801\left(\mathrm{t}, 2 \mathrm{H}, J=6.0 \mathrm{~Hz}\right.$, Phth- $\left.\mathrm{CH}_{2} \mathrm{CH}_{2} \mathrm{~N}\right), 7.25-7.36$ (m, 5H, Ph- $\left.\mathrm{CH}_{2}\right), 7.80-7.90$ (m, 4H, Phth). M/z (ESI-MS): $350(\mathrm{M}+\mathrm{H})^{+}$.

2-((1-Benzylpiperidine-3-yl)methyl)isoindoline-1,3-dione (3a). Starting from 3-(aminomethyl)piperidine and afterwards benzyl bromide, the crude solid compound was purified by chromatography column (with eluent $\mathrm{ACN} / \mathrm{H}_{2} \mathrm{O}, 7 / 1$ ) affording the pure title compound as yellow solid ( $\left.\eta=40 \%\right) .{ }^{1} \mathrm{H}$ RMN (300 MHz, MeOD- $\left.d_{4}\right), \delta(\mathrm{ppm}): 1.41-1.46,1.71-1.99,2.20-2.27(\mathrm{~m}, 9 \mathrm{H}$, piperidine), 2.88 (d, 2H, $\left.J=12.0 \mathrm{~Hz}, \mathrm{NCH}_{2} \mathrm{CH}\right), 3.49$ (s, 2H, NCH $\left.\mathrm{Nh}_{2} \mathrm{Ph}\right), 7.40-7.57$ (m, 9H, $\mathrm{PhCH}_{2}$, Phth). M/z (ESI-MS): 335 $(\mathrm{M}+1)^{+}$.

2-((1-Benzylpiperidine-2-yl)methyl)isoindoline-1,3-dione (4a). Starting from 2-(aminomethyl)piperidine and afterwards benzyl bromide, the crude solid compound was purified by recrystallization $\mathrm{ACN} / \mathrm{MeOH}$, affording a pure compound as a yellow solid $\left(\eta=43 \%\right.$, M.P. $\left.=130{ }^{\circ} \mathrm{C}\right) .{ }^{1} \mathrm{H}$ RMN $\left(300 \mathrm{MHz}, \mathrm{MeOD}-d_{4}\right)$, $\delta(\mathrm{ppm}): 1.37-1.80(\mathrm{M}, 6 \mathrm{H}$, piperidine), $2.02(\mathrm{t}, 2 \mathrm{H}, J=12.0 \mathrm{~Hz}$, piperidine, $2.91(\mathrm{~m}, 1 \mathrm{H}$, piperidine), $3.51\left(\mathrm{~s}, 2 \mathrm{H}, \mathrm{CH}_{2} \mathrm{Ph}\right), 3.58\left(\mathrm{~d}, 2 \mathrm{H}, \mathrm{J}=12.0 \mathrm{~Hz}, \mathrm{NCH}_{2} \mathrm{CH}\right), 7.34-7.29(\mathrm{~m}, 5 \mathrm{H}, \mathrm{Ph}), 7.89-7.79$ (m, 4H, Phth); $\mathrm{M} / \mathrm{z}$ (ESI-MS): $335(\mathrm{M}+1)^{+}$.

2-(2-(4-(2-Fluorobenzyl)piperazin-1-yl)ethyl)isoindoline-1,3-dione (10a). Starting from 1-(2-aminoethyl)piperazine and afterwards 2-fluorobenzyl-bromide, the crude solid compound was purified by washing with methanol, affording a pure compound as a beige solid $\left(\eta=25 \%\right.$, M.P. $\left.=93-95^{\circ} \mathrm{C}\right) . \mathrm{H}^{1} \mathrm{NMR}(300 \mathrm{MHz}$, DMSO- $\left.d_{6}\right), \delta(\mathrm{ppm}): 2.21-2.50\left(\mathrm{~m}, 10 \mathrm{H}\right.$, piperazine, $\left.\mathrm{CH}_{2} \mathrm{~N}\right), 3.68\left(\mathrm{t}, 2 \mathrm{H}, J=6 \mathrm{~Hz}, \mathrm{CH}_{2} \mathrm{NPhth}\right), 7.18-7.11$, 7.40-7.27 ( $2 \times \mathrm{m}, 4 \mathrm{H}, \mathrm{Ph}), 7.82-7.88$ (m, 4H, Phth). M/z (ESI-MS): $368.36(\mathrm{M}+1)^{+}$.

2-(2-(4-(2-Nitrobenzyl)piperazin-1-yl)ethyl)isoindoline-1,3-dione (11a). Starting from 1-(2-aminoethyl)piperazine and afterwards 2-nitrobenzyl-bromide, the crude has been purified by washing with methanol affording a pure compound as a light yellow solid $\left(\eta=28 \%\right.$, M.P. $\left.=100-103^{\circ} \mathrm{C}\right) . \mathrm{H}^{1} \mathrm{NMR}\left(300 \mathrm{MHz}, \mathrm{MeOD}-d_{4}\right)$, $\delta$ (ppm): $2.26-2.58(\mathrm{~m}, 8 \mathrm{H}, \mathrm{H} 8-11), 2.63\left(\mathrm{t}, 2 \mathrm{H}, J=8 \mathrm{~Hz}, \mathrm{CH}_{2} \mathrm{~N}\right), 3.74\left(\mathrm{~s}, 2 \mathrm{H}, \mathrm{NCH} \mathrm{H}_{2} \mathrm{Ph}\right), 3.80(\mathrm{t}, 2 \mathrm{H}, J=8$ $\left.\mathrm{Hz}, \mathrm{CH}_{2} \mathrm{NPhth}\right), 7.48-7.42,7.56-7.61(2 \times \mathrm{m}, 4 \mathrm{H}, \mathrm{Ph}), 7.78-7.86$ (m, 4H, Phth). M/z (ESI-MS): 395.38 $(\mathrm{M}+1)^{+}$.

2-(2-(4-(Pyridin-2-ylmethyl)piperazin-1-yl)ethyl)isoindoline-1,3-dione (12a). Starting from 1-(2-aminoethyl) piperazine and afterwards 2-(bromomethyl)pyridine- $\mathrm{HBr}$, the crude has been purified by washing with ether, affording a pure compound as a beige solid $\left(\eta=20 \%\right.$, M.P. $\left.=93-95^{\circ} \mathrm{C}\right) . \mathrm{H}^{1} \mathrm{NMR}(400 \mathrm{MHz}$, MeOD- $\left.d_{4}\right) \delta(\mathrm{ppm}): 2$. 50-2.62 (m, 8H, piperazine), $2.66\left(\mathrm{t}, 2 \mathrm{H}, J=8 \mathrm{~Hz}, \mathrm{CH}_{2} \mathrm{~N}\right), 3.63\left(\mathrm{~s}, 2 \mathrm{H}, \mathrm{CH}_{2} \mathrm{Ph}\right)$. $3.82\left(\mathrm{t}, 2 \mathrm{H}, J=8 \mathrm{~Hz}, \mathrm{CH}_{2} \mathrm{NPhth}\right), 7.28-7.33$ (m, 1H, H2-py), 7.51 (d, 1H, J = $\left.4 \mathrm{~Hz}, \mathrm{H} 4-\mathrm{Py}\right), 7.86-7.78$ (m, 1+4 H, H3-Py + Phth), 8.66 (d, 1H, J = 4 Hz, H1-Py). M/z (ESI-MS): $351.36(\mathrm{M}+1)^{+}$.

3.2.1.3. Deprotection of Primary Amine from the Isoindoline-1,3-Diones $(\mathbf{1} \mathbf{b}-\mathbf{4} \mathbf{b}, \mathbf{1 0 b}-\mathbf{1 2} \mathbf{b})$

General Procedure

The benzylpiperidine- or benzylpiperazine- or methylpyridinepiperazine-isoindoline-1,3-dione derivatives (1a-4a; 10a-12a) (1 eq) and hydrazine monohydrate (6 eq) were dissolved in absolute 
ethanol and warmed at $60^{\circ} \mathrm{C}$ for $3 \mathrm{~h}$. The reaction mixture was then filtered and the liquid filtrate was concentrated under reduced pressure. The residue was dissolved in ethyl acetate, washed with brine (three times), dried over anhydrous sodium sulphate, and concentrated under reduced pressure obtaining a yellow oil $(\eta=35-79 \%)$.

(1-Benzylpiperidin-4-yl)methanamine (1) Starting from 1a, the pure compound was obtained as a yellow oil $(\eta=40 \%) .{ }^{1} \mathrm{H}$ RMN (300 MHz, DMSO- $\left.d_{6}\right), \delta$ (ppm): 1.25-1.39, 1.58-1.69, 1.79-1.91 e 2.36-2.41 (m, $9 \mathrm{H}$, piperidine), $2,77\left(\mathrm{~d}, 2 \mathrm{H}, J=12.0 \mathrm{~Hz}, \mathrm{NCH}_{2} \mathrm{CH}\right), 3.42\left(\mathrm{~s}, 2 \mathrm{H}, \mathrm{NCH}_{2} \mathrm{Ph}\right), 7.19-7.36\left(\mathrm{~m}, 5 \mathrm{H}, \mathrm{Ph}_{-} \mathrm{CH}_{2}\right)$. M/z (ESI-MS): $205.00(\mathrm{M}+1)^{+}$.

2-(4-Benzylpiperazin-1-yl)ethanamine (2b). Starting from 1a, the pure compound was obtained as a yellow oil $(\eta=36 \%) .{ }^{1} \mathrm{H}$ NMR $\left(300 \mathrm{MHz}, \mathrm{MeOD}-d_{4}\right), \delta(\mathrm{ppm}): 2.45\left(\mathrm{t}, 2 \mathrm{H}, J=6 \mathrm{~Hz}, \mathrm{NH}_{2} \mathrm{CH}_{2} \mathrm{CH}_{2} \mathrm{~N}\right)$, 2.60-2.52 (m, 8H, piperazine), $2.75\left(\mathrm{t}, 2 \mathrm{H}, \mathrm{J}=6 \mathrm{~Hz}, \mathrm{NH}_{2} \mathrm{CH}_{2} \mathrm{CH}_{2} \mathrm{~N}\right), 3.53\left(\mathrm{~s}, 2 \mathrm{H}, \mathrm{NCH}_{2} \mathrm{Ph}\right), 7.21-7.37$ (m, 5H, Ph). M/z (ESI-MS): $220(\mathrm{M}+1)^{+}$.

(1-Benzylpiperidin-3-yl)methanamine (3b). Starting from 3a, the title pure product was obtained $(\eta=37 \%)$. ${ }^{1} \mathrm{H}$ RMN (300 MHz, MeOD- $\left.d_{4}\right), \delta$ (ppm): 1.69-1.96, 2.32-2.39 (m, 7H, piperidine), $2.54(\mathrm{t}, 2 \mathrm{H}, J=12 \mathrm{~Hz}$, piperidine), $2.97\left(\mathrm{~d}, 2 \mathrm{H}, J=9 \mathrm{~Hz}, \mathrm{NCH}_{2} \mathrm{CH}\right), 3.56\left(\mathrm{~s}, 2 \mathrm{H}, \mathrm{NCH}_{2} \mathrm{Ph}\right), 7.81-7.90$ (m, 5H, Ph). M/z (ESI-MS): $205(\mathrm{M}+1)^{+}$.

(1-Benzylpiperidin-2-yl)methanamine (4b). Starting from $4 \mathbf{a}$, the pure title product was obtained $(\eta=35 \%)$. ${ }^{1} \mathrm{H}$ RMN (300 MHz, MeOD- $\left.d_{4}\right), \delta(\mathrm{ppm}): 1.24-1.86(2 \times \mathrm{m}, 6 \mathrm{H}$, piperidina), $2.40(\mathrm{t}, 2 \mathrm{H}, J=12.0 \mathrm{~Hz}$ piperidina), $2.78(\mathrm{~m}, 1 \mathrm{H}, J=12.0 \mathrm{~Hz}, \mathrm{NCH} 2 \mathrm{CH}), 2.91(\mathrm{~m}, 1 \mathrm{H}$, piperidina), $3.51(\mathrm{~s}, 2 \mathrm{H}, \mathrm{NCH} 2 \mathrm{Ph})$, 7.34-7.19 (m, 5H, Ph). M/z (ESI-MS): $205(\mathrm{M}+1)^{+}$.

2-(4-(2-Fluorobenzyl)piperazin-1-yl)ethanamine (10b). Starting from 10a, $\eta=73 \% .{ }^{1} \mathrm{H}$ NMR $(400 \mathrm{MHz}$, MeOD- $\left.d_{4}\right), \delta(\mathrm{ppm}): 2.46\left(\mathrm{t}, 2 \mathrm{H}, J=8 \mathrm{~Hz}, \mathrm{NCH}_{2} \mathrm{CH}_{2} \mathrm{NH}_{2}\right), 2.69-2.48(\mathrm{~m}, 8 \mathrm{H}$, piperazine), 2.74-2.78 (t, $\left.2 \mathrm{H}, J=8 \mathrm{~Hz}, \mathrm{NCH}_{2} \mathrm{CH}_{2} \mathrm{NH}_{2}\right), 3.62\left(\mathrm{~s}, 2 \mathrm{H}, \mathrm{NCH}_{2} \mathrm{Ph}\right), 7.06-7.10,7.13-7.17,7.28-7.33,7.38-7.42(4 \times \mathrm{m}$, $4 \mathrm{H}, \mathrm{Ph}) . \mathrm{M} / \mathrm{z}$ (ESI-MS): $238.22(\mathrm{M}+1)^{+}$.

2-(4-(2-Nitrobenzyl)piperazin-1-yl)ethanamine (11b). Starting from 11, $\eta=79 \% .{ }^{1} \mathrm{H}$ NMR $(300 \mathrm{MHz}$, MeOD- $\left.d_{4}\right), \delta(\mathrm{ppm}): 2.41-2.55\left(\mathrm{~m}, 10 \mathrm{H}\right.$, Pyridine+ $\left.\mathrm{NCH}_{2} \mathrm{CH}_{2} \mathrm{NH}_{2}\right), 2.74\left(\mathrm{t}, 2 \mathrm{H}, J=6 \mathrm{~Hz}, \mathrm{NCH}_{2} \mathrm{CH}_{2} \mathrm{NH}_{2}\right)$, 3.79 (s, 2H, $\left.\mathrm{CH}_{2} \mathrm{Ph}\right), 7.44-7.50,7.58-7.60$ (m, 3H, Ph), 7.81 (d, 1H, J = 9 Hz, Ph). M/z (ESI-MS): 265 $(\mathrm{M}+1)^{+}$.

2-(4-(Pyridin-2-ylmethyl)piperazin-1-yl)ethanamine (12b). Starting from 12a, $\eta=36.3 \% .{ }^{1} \mathrm{H} \mathrm{NMR}(300 \mathrm{MHz}$, MeOD- $\left.d_{4}\right), \delta(\mathrm{ppm}): 2.45\left(\mathrm{t}, 2 \mathrm{H}, J=6 \mathrm{~Hz}, \mathrm{NCH}_{2} \mathrm{CH}_{2} \mathrm{NH}_{2}\right) 2.64-2.55(\mathrm{~m}, 8 \mathrm{H}$, piperazine), $2.74(\mathrm{t}, 2 \mathrm{H}, J=$ $6 \mathrm{~Hz}, \mathrm{NCH}_{2} \mathrm{CH}_{2} \mathrm{NH}_{2}$ ), 3.67 (s, 2H, $\left.\mathrm{CH}_{2} \mathrm{Py}\right), 7.30-7.34(\mathrm{~m}, 1 \mathrm{H}, \mathrm{Py}-\mathrm{H}-2), 7.54(\mathrm{~d}, 1 \mathrm{H}, J=6 \mathrm{~Hz}, \mathrm{Py}-\mathrm{H}-4)$, 7.80-7.85 (m, 1H, H3Py), 8.48 (d, 1H, $J=6$ Hz, Py-H-1). M/z (ESI-MS): $221(\mathrm{M}+1)^{+}$.

3.2.2. Synthesis of 2-(X-2-hydroxyphenyl)- $1 \mathrm{H}$-benzo[d]imidazole-5-carboxylic Acids $\left(\mathrm{X}=5-\mathrm{F}, 5-\mathrm{NO}_{2}\right.$, $4-\mathrm{OMe})$

General Procedure (Method B)

3,4-Diaminobenzoic acid (1 eq), a suitable salicylaldehyde (1 eq) and $\mathrm{Na}_{2} \mathrm{~S}_{2} \mathrm{O}_{5}$ (1.4 eq) were dissolved in choline chloride/glycerol (1:2), mol/mol) and warmed at $50{ }^{\circ} \mathrm{C}$ for $30 \mathrm{~min}$. Then the reaction mixture was cooled at $\mathrm{rt}$, added to water and filtrated. The solid obtained was washed with dichloromethane, affording beige-yellow solids with yield $67 \%-97 \%$.

2-(5-Fluoro-2-hydroxyphenyl)-1H-benzo[d]imidazole-5-carboxylic acid (6c). Starting from 5-fluorosalicylaldehyde, the title compound was obtained as a beige solid $(\eta=97 \%)$, M.P. $=250{ }^{\circ} \mathrm{C} .{ }^{1} \mathrm{H}$ NMR (300 MHz, DMSO- $\left.d_{6}\right), \delta(\mathrm{ppm}): 7.08(\mathrm{~s}, 1 \mathrm{H}, \mathrm{BIM}-\mathrm{H}-7) 7.26(\mathrm{~d}, 1 \mathrm{H}, J=6.0 \mathrm{~Hz}, \mathrm{BIM}-\mathrm{H}-4), 7.74(\mathrm{~d}$, $1 \mathrm{H}, J=6.0 \mathrm{~Hz}, \mathrm{BIM}-\mathrm{H}-5), 7.91(\mathrm{~d}, 1 \mathrm{H}, J=9.0 \mathrm{~Hz}, \mathrm{BIM}-\mathrm{H}-2), 8.00(\mathrm{~d}, 1 \mathrm{H}, J=9.0 \mathrm{~Hz}, \mathrm{BIM}-\mathrm{H}-3), 8.25(\mathrm{~s}, 1 \mathrm{H}$, BIM-H-1), 12.78 (s, 1H, COOH). M/z (ESI-MS): $273(\mathrm{M}+1)^{+}$. 
2-(5-Nitro-2-hydroxyphenyl)-1H-benzo[d]imidazole-5-carboxylic acid (7c). Starting from 5-nitrosalicylaldehyde, the title compound was obtained as a beige solid $(\eta=78 \%)$, M.P. $>300{ }^{\circ} \mathrm{C} .{ }^{1} \mathrm{H}$ NMR (300 MHz, DMSO- $\left.d_{6}\right), \delta$ (ppm): 7.06-7.11 (m, 1H, BIM-H-2), 7.25-7.32 (m, 1H, BIM-H-4), 7.73-7.76 (d, 1H, J = 9.0 Hz, BIM-H-2), 7.89-7.96 (m, 2H, BIM-H-1, BIM-H-5), 8.24 (s, 1H, BIM-H-7), $12.78(\mathrm{~s}, 1 \mathrm{H}, \mathrm{COOH}) . \mathrm{M} / \mathrm{z}(\mathrm{ESI}-\mathrm{MS}): 300(\mathrm{M}+1)^{+}$.

2-(4-Metoxy-2-hydroxyphenyl)-1H-benzo[d]imidazole-5-carboxylic acid (9c). Starting from 4-metoxysalicylaldehyde, the title compound was obtained as a beige solid $(\eta=67 \%)$, M.P. $>300{ }^{\circ} \mathrm{C} .{ }^{1} \mathrm{H}$ NMR (300 MHz, DMSO- $\left.d_{6}\right), \delta(\mathrm{ppm}): 3.82\left(\mathrm{sg}, 3 \mathrm{H}, \mathrm{OCH}_{3}\right), 6.62(\mathrm{~s}, 1 \mathrm{H}, \mathrm{BIM}-\mathrm{H}-4) 6.66(\mathrm{~d}, 1 \mathrm{H}, J=9.0 \mathrm{~Hz}$, BIM-H-6), 7.68 (d, 1H, J =9.0 Hz, BIM-H-7), $7.88(\mathrm{~d}, 1 \mathrm{H}, J=9.0 \mathrm{~Hz}, \mathrm{BIM}-\mathrm{H}-2), 7.98(\mathrm{~d}, 1 \mathrm{H}, J=9.0 \mathrm{~Hz}$, BIM-H-3), 8.18 (s, 1H, BIM-H-1), 12.96 (s, 1H, COOH). M/z (ESI-MS): $285(\mathrm{M}+1)^{+}$.

\subsubsection{Synthesis of the Final Conjugates (1-12)}

General Procedure

To a solution of the carboxylic acid derivatives $(\mathbf{1 c}, \mathbf{5 c}, \mathbf{6 c}, \mathbf{7 c}, \mathbf{9 c})(1 \mathrm{eq})$ and the amine derivatives (1-4b, 10-12b) (1 eq) in anhydrous DMF, was added $N$-hydroxysuccinimide (1 eq) and DCC (1 eq) and the reaction mixture was left stirring for $24 \mathrm{~h}$ at rt. Then, the precipitate obtained (urea) was filtered off and the liquid phase was diluted with ethyl acetate and washed with brine (three times). The combined organic phase was dried over anhydrous $\mathrm{Na}_{2} \mathrm{SO}_{4}$, concentrated under reduced pressure, and purified by recrystallisation in $\mathrm{EtOAc}$ or $\mathrm{Et}_{2} \mathrm{O}$ and $\mathrm{ACN} / \mathrm{MeOH}$, or column chromatography, affording the pure final conjugate as a solid.

N-((1-Benzylpiperidin-3-yl)methyl)-2-(2-hydroxyphenyl)-1H-benzo[d]imidazole-6-carboxamide (3). Starting from $3 \mathbf{b}$ and $1 \mathbf{c}$, the title compound was obtained as a beige solid $(\eta=22 \%)$, M.P. $=220-222{ }^{\circ} \mathrm{C}$. ${ }^{1} \mathrm{H}$ RMN (300 MHz, MeOD- $\left.d_{4}\right), \delta(\mathrm{ppm}): 1.49-1.94\left(\mathrm{~m}, 5 \mathrm{H}\right.$, piperidine), 2.64- $2.89\left(\mathrm{~m}, 4 \mathrm{H}, \mathrm{NCH}_{2}\right.$ (piperidine)), $3.18\left(\mathrm{~m}, 2 \mathrm{H}, \mathrm{NHCH}_{2}, 3.53\left(\mathrm{~s}, 2 \mathrm{H}, \mathrm{NCH}_{2} \mathrm{Ph}\right):{ }^{13} \mathrm{C} \mathrm{RMN}\left(75.5 \mathrm{MHz}, \mathrm{MeOD}-d_{4}\right), \delta(\mathrm{ppm})\right.$ : 25.41, 27.80, 29.32, 43.06, 56.94, 59.71, 64.82, 114.2, 116.4, 117.9, 118.4, 121.9, 122.4, 127.6, 128.2, 128.9, $129.8,130.3,131.8,139.0,145.3,152.7,154.1,166.9 . \mathrm{M} / \mathrm{z}$ (ESI-MS): $441.36(\mathrm{M}+1)^{+}$.

N-((1-Benzylpiperidin-2-yl)methyl)-2-(2-hydroxyphenyl)-1H-benzo[d]imidazole-6-carboxamide (4). Starting from $4 b$ and $1 c$, the title compound was obtained as a beige solid $(\eta=25 \%)$, M. P. $=226-227^{\circ} \mathrm{C}$. ${ }^{1} \mathrm{H}$ NMR (300 MHz, DMSO- $\left.d_{6}\right), \delta$ (ppm): 1.24-1.71 (m, 6H, Pip), 2.63-2.73 (m, 3H, Pip), 3.42 (d, 2H, $\left.J=12 \mathrm{~Hz}, \mathrm{CHCH}_{2} \mathrm{~N}\right), 3.64\left(\mathrm{~s}, 2 \mathrm{H}, \mathrm{CH}_{2} \mathrm{Ph}\right), 4.05(\mathrm{sb}, 1 \mathrm{H}, \mathrm{NH}), 7.05-7.08(\mathrm{~m}, 2 \mathrm{H}, \mathrm{H} 24, \mathrm{H} 26), 7.23-7.45$ (m, 6H, H1 a H5 e H25), 7.65 (d, 1H, J = 6 Hz, H27), $7.80(\mathrm{~d}, 1 \mathrm{H}, J=6 \mathrm{~Hz}, \mathrm{H} 18), 8.09(\mathrm{~d}, 1 \mathrm{H}, J=9 \mathrm{~Hz}$, H19), 8.26 (s, 1H, H16), 8.41 (s, 1H, NH). ${ }^{13} \mathrm{C}$ NMR (75.5 MHz, DMSO-d 6 ), $\delta$ (ppm): 22.75, 24.38, 28.96, 33.96, 50.01 50.58, 60.08, 111.56, 112.94, 117.36, 117.73, 119.74, 122.14, 123.43, 127.00, 128.57, 128.97, 132.60, 135.69, 140.15, 141.03, 153.79, 158.47, 166.91. M/z (ESI-MS): $441.24(\mathrm{M}+1)^{+}$.

N-((1-Benzylpiperidin-4-yl)methyl)-2-(2-hydroxy-5-fluorophenyl)-1H-benzo[d]imidazole-5-carboxamide (6). Starting from $\mathbf{1 b}$ and $\mathbf{6 c}$, the title compound was obtained as a white solid $(\eta=24 \%)$ M.P. $=241-243^{\circ} \mathrm{C}$. ${ }^{1} \mathrm{H}$ NMR (300 MHz, MeOD- $\left.d_{4}\right), \delta$ (ppm): 1.01-1.24 (m, 4H, piperidine), $163-1.91$ (m, $5 \mathrm{H}$, piperidine), $2.81(\mathrm{~d}, 2 \mathrm{H}, J=12.0 \mathrm{~Hz}, \mathrm{NCH} 2 \mathrm{CH}), 3.49$ (s, 2H, NCH2Ph), 5.59 (b, 1H, NH), 7.12-7.03 (m, 2H, BIM-H-5,6) 7.19-7.39 (m, 5H, Ph-CH2), 7.69 (s, 1H, BIM-H-7), 7.81 (d, 1H, J = 8.0 Hz, BIM-H-4), 7.93 (d, 1H, $J=8.0 \mathrm{~Hz}, \mathrm{BIM}-\mathrm{H}-3), 8.51$ (s, $1 \mathrm{H}, \mathrm{BIM}-\mathrm{H}-2) .{ }^{13} \mathrm{C}$ NMR $\left(100 \mathrm{MHz}, \mathrm{MeOD}-d_{4}\right), \delta$ (ppm): 27.3, 37.2, 43.2, 53.1, 63.3, 115.2, 116.5, 117.6, 119.9, 122.3, 126.6, 128.2, 128.9, 132.3, 138.4, 146.2, 149.3, 151.3, 152.7, 166.8 . $\mathrm{M} / \mathrm{z}$ (ESI-MS): $459.23(\mathrm{M}+1)^{+}$.

N-(2-(4-Benzylpiperazin-1-yl)ethyl)-2-(2-hydroxy-5-nitrophenyl)-1H-benzo[d]imidazole-5-carboxamide (7). Starting from $\mathbf{2 b}$ and $\mathbf{7 c}$, with final purification through column chromatography (eluent: DCM/MeOH 98:2) afforded a yellow solid $(\eta=28 \%)$, M.P. $=225-227^{\circ} \mathrm{C} .{ }^{1} \mathrm{H}$ NMR $\left(300 \mathrm{MHz}, \mathrm{MeOD}-d_{4}\right), \delta(\mathrm{ppm})$ : 2.77-2.94 (m, 10H, 8 piperazine $\left.+2 \mathrm{NH}_{2} \mathrm{CH}_{2} \mathrm{CH}_{2} \mathrm{~N}\right), 3.66-3.75\left(\mathrm{~m}, 4 \mathrm{H}, \mathrm{NCH}_{2} \mathrm{Ph}\right.$ and $\left.\mathrm{NH}_{2} \mathrm{CH}_{2} \mathrm{CH}_{2} \mathrm{~N}\right)$, 7.07-7.38, 7.77-7.83, and 8.18-9.05 $(3 \times \mathrm{m}, 11 \mathrm{H}, \mathrm{Ar}-\mathrm{H}) .{ }^{13} \mathrm{C}$ NMR (100 MHz, MeOD- $\left.d_{4}\right), \delta$ (ppm): 30.3, 
36.2, 45.7, 53.6, 62.8, 113.3, 117.8, 119.5, 127.0, 127.3, 128.6, 129.3, 129.8, 132.5, 139.1, 143.9, 157.1, 160.8, 167.9. $\mathrm{M} / \mathrm{z}$ (ESI-MS): $501.24(\mathrm{M}+1)^{+}$.

N-(2-(4-Benzylpiperazin-1-yl)ethyl)-2-(2-hydroxy-5-fluorophenyl)-1H-benzo[d]imidazole-5-carboxamide (8). Starting from $\mathbf{2 b}$ and $\mathbf{6 c}$, with final recrystallization from $\mathrm{ACN} / \mathrm{MeOH}$, afforded the title compound as a white-beige solid $(\eta=27 \%)$ M.P. $=246-248{ }^{\circ} \mathrm{C} .{ }^{1} \mathrm{H}$ NMR $\left(300 \mathrm{MHz}, \mathrm{MeOD}-d_{4}\right), \delta(\mathrm{ppm}): 2.77-2.94$ $\left(\mathrm{m}, 10 \mathrm{H}\right.$, piperazine $\left.+2 \mathrm{NH}_{2} \mathrm{CH}_{2} \mathrm{CH}_{2} \mathrm{~N}\right), 3.66-3.75\left(\mathrm{~m}, 4 \mathrm{H}, 2 \mathrm{NCH}_{2} \mathrm{Ph}+2 \mathrm{NH}_{2} \mathrm{CH}_{2} \mathrm{CH}_{2} \mathrm{~N}\right), 7.03-7.20$, 7.34-7.37, and 7.69-8.16 (m, 11H, Ar-H). ${ }^{13} \mathrm{C}$ NMR (100 MHz, MeOD- $\left.d_{4}\right), \delta$ (ppm): 30.3, 36.2, 45.7, 53.6, 62.8, 113.3, 117.8, 119.5, 127.0, 127.3, 128.6, 129.3, 129.8, 132.5, 139.1, 154.6, 157.1, 160.8, 167.9. M/z (ESI-MS): $474.22(\mathrm{M}+1)^{+}$.

N-(2-(4-Benzylpiperazin-1-yl)ethyl)-2-(4-metoxy-2-hydroxyphenyl)-1H-benzo[d]imidazole-5-carboxamide (9). Starting from $\mathbf{2 b}$ and $\mathbf{9 c}$, with final recrystallization from $\mathrm{ACN} / \mathrm{MeOH}$ afforded the pure title compound as white solid $(\eta=32 \%)$, M.P. $=249-251{ }^{\circ} \mathrm{C} .{ }^{1} \mathrm{H}$ NMR $\left(300 \mathrm{MHz}, \mathrm{MeOD}-d_{4}\right), \delta(\mathrm{ppm}): 2.77-2.94(\mathrm{~m}, 10 \mathrm{H}$, piperazine $\left.+\mathrm{NH}_{2} \mathrm{CH}_{2} \mathrm{CH}_{2} \mathrm{~N}\right), 3.66-3.75\left(\mathrm{~m}, 4 \mathrm{H}, 2 \mathrm{NCH}_{2} \mathrm{Ph}+2 \mathrm{NH}_{2} \mathrm{CH}_{2} \mathrm{CH}_{2} \mathrm{~N}\right), 3.87\left(\mathrm{~s}, 3 \mathrm{H}, \mathrm{OCH}_{3}\right)$, 6.70-6.74, 7.29-7.36, and 7.61-8.10 $(3 \times \mathrm{m}, 11 \mathrm{H}, \mathrm{Ar}-\mathrm{H}) .{ }^{13} \mathrm{C}$ NMR $\left(100 \mathrm{MHz}, \mathrm{MeOD}-d_{4}\right), \delta(\mathrm{ppm}): 30.3$, 36.2, 45.7, 53.6, 62.8, 113.3, 117.8, 119.5, 127.0, 127.3, 128.6, 129.3, 129.8, 132.5, 139.1, 157.1, 160.8, 162.1, 167.9. $\mathrm{M} / \mathrm{z}$ (ESI-MS): $486.25(\mathrm{M}+1)^{+}$.

N-(2-(4-(2-Fluorobenzyl)piperazin-1-yl)ethyl)-2-(2-hydroxyphenyl)-1H-benzo[d]imidazole-6-carboxamide (10). Starting from $10 \mathbf{b}$ and $1 c$, the pure product was purified by column chromatography (eluent: $\mathrm{ACN} / \mathrm{H}_{2} \mathrm{O}$, 9:1) $(\eta=47 \%)$, M.P. $=219-222{ }^{\circ} \mathrm{C} .{ }^{1} \mathrm{H}$ NMR $\left(400 \mathrm{MHz}, \mathrm{MeOD}-d_{4}\right), \delta(\mathrm{ppm}): 2.63-2.90(\mathrm{~m}, 10 \mathrm{H}$, piperazine $\left.+\mathrm{NCH}_{2} \mathrm{CH}_{2} \mathrm{NH}\right), 3.62\left(\mathrm{t}, 2 \mathrm{H}, J=6 \mathrm{~Hz}, \mathrm{NCH}_{2} \mathrm{CH}_{2} \mathrm{NH}\right), 3.72\left(\mathrm{~s}, 2 \mathrm{H}, \mathrm{NCH}_{2} \mathrm{Ph}\right), 6.98-7.20(\mathrm{~m}$, $4 \mathrm{H}, \mathrm{H} 4-5, \mathrm{H} 24, \mathrm{H} 26), 7.30-7.44(\mathrm{~m}, 3 \mathrm{H}, \mathrm{H} 1-2, \mathrm{H} 14), 7.67$ (d, 1H, J = 9 Hz, H27), 7.78 (d, 1H, J = 6 Hz, H16), 7.97 (d, $1 \mathrm{H}, J=9 \mathrm{~Hz}, \mathrm{H} 17), 8.14(\mathrm{~s}, 1 \mathrm{H}, \mathrm{H} 20) .{ }^{13} \mathrm{C}$ NMR (100 MHz MeOD- $\left.d_{4}\right), \delta$ ppm: 36.26, 51.65, 52.30, 54.32, 56.78, 112.62, 114.87, 115.05, 117.34, 119.41, 123.88, 126.32, 131.88, 132.12, 158.18. M/z (ESI-MS): $474.31(\mathrm{M}+1)^{+}$.

2-(2-Hydroxyphenyl)-N-(2-(4-(2-nitrobenzyl)piperazin-1-yl)ethyl)-1H-benzo[d]imidazole-6-carboxamide (11). Starting from $\mathbf{1 1} \mathbf{b}$ and $\mathbf{1} \mathbf{c}$ the pure title product was purified by column chromatography (eluent: $\mathrm{AcOEt} / \mathrm{MeOH}, 9: 1),(\eta=40 \%)$, M.P. $=242-244{ }^{\circ} \mathrm{C} .{ }^{1} \mathrm{H}$ NMR $\left(400 \mathrm{MHz}, \mathrm{DMSO}-d_{6}\right), \delta(\mathrm{ppm}): 2.36-2.53$ $\left(\mathrm{m}, 10 \mathrm{H}\right.$, piperazine $\left.+\mathrm{NCH}_{2} \mathrm{CH}_{2} \mathrm{NH}\right) 3.63-3.74\left(\mathrm{~m}, 4 \mathrm{H}, \mathrm{NCH}_{2} \mathrm{Ph}+\mathrm{NCH}_{2} \mathrm{CH}_{2} \mathrm{NH}\right), 5.51(\mathrm{~s}, 1 \mathrm{H}, \mathrm{OH})$, 8.39 (s, 1H, H20), 7.01-7.06 (m, 2H, H24 and H26), 7.39-7.42 (m, 1H, H25), 7.50-7.53 (m, 1H, H27), $7.60-7.70(\mathrm{~m}, 3 \mathrm{H}, \mathrm{H} 3, \mathrm{H} 4$ and $\mathrm{H} 5), 7.78(\mathrm{~d}, 2 \mathrm{H}, J=8 \mathrm{~Hz}, \mathrm{H} 2), 7.85(\mathrm{~d}, 2 \mathrm{H}, J=8 \mathrm{~Hz}, \mathrm{H} 16), 8.08(\mathrm{~d}, 2 \mathrm{H}$, $J=8 \mathrm{~Hz}, \mathrm{H} 17), 8.14$ (s, $1 \mathrm{H}, \mathrm{C}-\mathrm{CH}-\mathrm{C}) .{ }^{13} \mathrm{C}$ NMR $\left(100 \mathrm{MHz}, \mathrm{DMSO}-d_{6}\right), \delta$ ppm: 34.36, 35.31, 42.99, 46.81, $62.49,66.87,68.25,122.48,123.62,127.31,129.13,134.07,136.31,138.42,140.98,142.11,142.38,142.85$, 157.52, 157.80, 159.61, 166.38, 167.80, 176.01. M/z (ESI-MS): $501.29(\mathrm{M}+1)^{+}$.

2-(2-Hydroxyphenyl)-N-(2-(4-(pyridin-2-ylmethyl)piperazin-1-yl)ethyl)-1H-benzo[d]imidazole-6-carboxamide (12). Starting from $\mathbf{1 2 b}$ and $\mathbf{1 c}$ the title product was purified by recrystallization from $\mathrm{ACN} / \mathrm{MeOH}$, $(\eta=41 \%)$, M.P. $=220-222{ }^{\circ} \mathrm{C} .{ }^{1} \mathrm{H}$ NMR $\left(300 \mathrm{MHz}, \mathrm{MeOD}-d_{4}\right), \delta(\mathrm{ppm}): 2.50-2.62(\mathrm{~m}, 8 \mathrm{H}$, piperazine), $2.66(\mathrm{t}, 2 \mathrm{H}, J=6 \mathrm{~Hz}, \mathrm{H} 11), 3.58(\mathrm{t}, 2 \mathrm{H}, J=6 \mathrm{~Hz}, \mathrm{H} 12), 3.68\left(\mathrm{~s}, 2 \mathrm{H}, \mathrm{NCH}_{2} \mathrm{Ph}\right), 6.97-7.05(\mathrm{~m}, 2 \mathrm{H}, \mathrm{H} 23$ and $\mathrm{H} 25), 7.3-7.4(\mathrm{~m}, 2 \mathrm{H}, \mathrm{H} 24$ and $\mathrm{H} 2), 7.54(\mathrm{~d}, 1 \mathrm{H}, J=9 \mathrm{~Hz}, \mathrm{H} 4), 7.66(\mathrm{~d}, 1 \mathrm{H}, J=9 \mathrm{~Hz}, \mathrm{H} 26), 7.76-7.85(\mathrm{~m}$, 2H, H3 and H17), $7.96(\mathrm{~d}, 1 \mathrm{H}, J=9 \mathrm{~Hz}, \mathrm{H} 18), 8.13(\mathrm{~s}, 1 \mathrm{H}, \mathrm{H1}), 8.47(\mathrm{~d}, 1 \mathrm{H}, J=6 \mathrm{~Hz}, \mathrm{H} 1) .{ }^{13} \mathrm{C} \mathrm{NMR}$ $\left(100 \mathrm{MHz}\right.$ MeOD- $\left.d_{4}\right)$, $\delta$ ppm: 36.49, 52.41, 52.73, 56.96, 63.20, 112.68, 116.80, 119.12, 121.93, 122.70, $123.71,126.29,128.83,131.85,137.11,148.25,149.64,153.83,155.50,157.68,158.44,161.24,169.17 . \mathrm{M} / \mathrm{z}$ (ESI-MS): $457.31(\mathrm{M}+1)^{+}$.

\subsection{Molecular Modeling: Docking and Pharmacokinetics Studies}

Docking simulations were carried out using the Gold v. 5.1 package of software [46]. The model structure for the active site of $\mathrm{AChE}$ was retrieved from the Brookhaven protein database (RCSB) (PDB, entry 1 EVE) [24], in particular, from the X-ray crystal structure of Torpedo Californica AChE (TcAChE) complexed with the cholinesterase inhibitor drug in clinical use (donepezil, DNP), hereinafter 
named as the original ligand. In spite of some known differences between the inhibitor-enzyme complexes, reported for the human acetylcholine esterase, $h \mathrm{AChE}$, and the electric ray homologue (Torpedo californica, TcAChE) both enzymes are quite conservative in terms of the main amino acid residues that line up the active site gorge [47], and so this docking study was performed with the TcAChE molecular model.

For the simulations, the original complex of TcAChE-DNP, retrieved from RCSB, was treated with MAESTRO v. 9.3 [48] to get the model structure of the receptor enzyme, by removing the original ligand (DNP), solvent and co-crystallization molecules, and subsequently adding hydrogen atoms. This program was also used to build the ligand structures which were then optimized (1000 cycles of random conformational search and 2500 optimization steps) with the program Ghemical v $2.0[49,50]$. The ligands were subsequently docked into the AChE active site, using GOLD program with the corresponding default parameters (except "allow early termination" option) and the Astex Statistical Potential (ASP) scoring function. The docking site was defined by establishing a box within $10 \AA$ from the original ligand in the above mentioned PDB structure. The first-ranked structures obtained from these calculations were then compared with the original ligand and analyzed in their interactions with the active site residues. The results were visualized using Chimera 1.6 [51].

Moreover, pharmacokinetic molecular descriptors were in silico evaluated. Parameters such as the octanol-water partition coefficient $(\operatorname{clog} P)$, blood-brain barrier partition coefficient $(\log B B)$, the ability to be absorbed through the intestinal tract (Caco-2 cell permeability), and CNS activity were calculated. The chemical structures were previously minimized in Maestro v. 9.3 [48] and then they were submitted to the calculation of these relevant pharmacokinetic properties and descriptors using QikProp v. 2.5 [43].

\subsection{Bio-Analytical Procedures}

\subsubsection{Inhibition of Acetylcholinesterase}

An adaptation of the Ellman's method, previously described, was used to measure the acetylcholinesterase inhibitory activity $[52,53]$. The assay solution contained $374 \mu \mathrm{L}$ of 4 -(2-hydroxyethyl)1-piperazineethanesulfonic acid (HEPES) buffer ( $50 \mathrm{mM}, \mathrm{pH} 8.0), 476 \mu \mathrm{L}$ of 5,5'-dithiobis-(2-nitrobenzoic acid) (DTNB, $3 \mathrm{mM})$, a variable volume (10-50 $\mu \mathrm{L})$ of the stock solution of each compound in methanol $(1 \mathrm{mg} / \mathrm{mL}), 25 \mu \mathrm{L}$ of AChE (type VI-S, from electric eel) stock solution, and the necessary amount of methanol to obtain $0.925 \mathrm{~mL}$ of sample mixture in a $1 \mathrm{~mL}$ cuvette. The samples were incubated for $15 \mathrm{~min}$ and then $75 \mu \mathrm{L}$ of acetylthiocholine iodide (AChI) solution $(16 \mathrm{mM})$ was added. The reaction was monitored for $5 \mathrm{~min}$ at $405 \mathrm{~nm}$. Assays were run with a blank containing all the components except AChE, which was replaced by HEPES buffer. The rates of the reaction were calculated as well as the enzyme activity. A control reaction was carried out using methanol as a sample solution and it was considered as $100 \%$ activity. The percentage inhibition of the enzyme activity due to the presence of increasing test compound concentration was calculated by the following Equation (1),

$$
\mathrm{I} \%=100-100 \times v_{\mathrm{i}} /\left(v_{\mathrm{i}}-v_{\mathrm{o}}\right)
$$

where $v_{\mathrm{i}}=$ starting reaction rate in the presence of inhibitor; $v_{\mathrm{o}}=$ starting reaction rate of the control reaction.

The inhibition curves were obtained by plotting the percentage of enzymatic inhibition versus inhibitor concentration and a calibration curve was got from which the linear regression parameters were obtained.

\subsubsection{Inhibition of Self- and Cu-Mediated $A \beta_{1-42}$ Aggregation}

The A $\beta$ peptide was treated with 1,1,1,3,3,3-hexafluoropropan-2-ol (HFIP) and dissolved in a $\mathrm{CH}_{3} \mathrm{CN} / \mathrm{Na}_{2} \mathrm{CO}_{3}(300 \mu \mathrm{M}) / \mathrm{NaOH}(250 \mu \mathrm{M})(48.3: 48.3: 4.3, v / v / v)$ mixture in order to have a stable stock 
solution, avoiding self-aggregation of $\mathrm{A} \beta_{1-42}$. Then, the prepared $500 \mu \mathrm{M}$ solution was diluted at 40 $\mu \mathrm{M}$ in phosphate buffer (0.215 $\mathrm{M}, \mathrm{pH} 8.0)$.

The solutions of the tested compounds were prepared in $\mathrm{MeOH}(1 \mathrm{mg} / \mathrm{mL})$, being further diluted in phosphate buffer to a concentration of $480 \mu \mathrm{M}$. For copper-induced aggregation studies, a solution of $\mathrm{CuCl}_{2} 240 \mu \mathrm{M}$ was prepared from a stock standard solution $(0.015 \mathrm{M})$. To perform the assays for the $\mathrm{A} \beta_{1-42}$ aggregation inhibition, a reported method, based on the fluorescence emission of thioflavin $\mathrm{T}$ (ThT), was followed $[36,37,54] . \mathrm{A} \beta_{1-42}(40 \mu \mathrm{M})$ was incubated at $37^{\circ} \mathrm{C}$, for $24 \mathrm{~h}$ with or without $\mathrm{Cu}(\mathrm{II})(40 \mu \mathrm{M})$ in a phosphate buffer in presence or absence of the single ligand $(40 \mu \mathrm{M}$ and $20 \mu \mathrm{M}$ for compound 4). Then, the samples were added to a 96-well plate with $180 \mu \mathrm{M}$ of $5 \mu \mathrm{M}$ ThT in $50 \mathrm{mM}$ glycine- $\mathrm{NaOH}$ ( $\mathrm{pH}$ 8.5) buffer. Blank samples were prepared without the peptide for each concentration. The ThT fluorescence was measured at $446 \mathrm{~nm}$ (excitation) and $485 \mathrm{~nm}$ (emission). The inhibition percentage of aggregation was calculated by Equation (2), in which $\mathrm{IF}_{\mathrm{i}}$ and $\mathrm{IF}_{0}$ corresponded to the fluorescence intensities, in the presence and in the absence of the tested compound, subtracted of the fluorescence intensities due to the respective blanks.

$$
\mathrm{I} \%=100-\left(\mathrm{IF}_{\mathrm{i}} / \mathrm{IF}_{0} \times 100\right)
$$

The reported values were obtained as the mean \pm SEM of duplicate of three different experiments.

\subsubsection{Metal Chelation}

Solutions: the aqueous copper $\left(\mathrm{CuCl}_{2}, 0.015 \mathrm{M}\right)$ and zinc $\left(\mathrm{ZnCl}_{2}, 0.0156 \mathrm{M}\right)$ stock solutions for potentiometric equilibrium studies were prepared from $1000 \mathrm{ppm}$ standards (Titrisol) and their metal content was evaluated by atomic absorption. The titrant solution $(0.1 \mathrm{M} \mathrm{KOH})$ was obtained from a carbonate-free commercial concentrate (Titrisol) and standardized by potentiometric titration with potassium hydrogen phthalate. The titrant solution was discarded whenever the percentage of carbonate (Gran's method) [55] was about $0.5 \%$ of the total amount of base.

Measurements: compounds 7 and 12 were titrated in $50 \%(w / w) D M S O / \mathrm{H}_{2} \mathrm{O}$ medium, at $T=25.0 \pm 0.1^{\circ} \mathrm{C}$ and ionic strength $(I) 0.1 \mathrm{M} \mathrm{KCl}$, using $0.1 \mathrm{M} \mathrm{KOH}$ as titrant. Both glass and $\mathrm{Ag} / \mathrm{AgCl}$ reference electrodes were previously conditioned in $\mathrm{DMSO} / \mathrm{H}_{2} \mathrm{O}$ mixtures with increasing amounts of DMSO and the response of the glass electrode was controlled by strong acid-strong base $(\mathrm{HCl} / \mathrm{KOH})$ calibrations with the determination of the Nernst parameters by Gran's method [55]. The measurements were performed in a final volume of $30.00 \mathrm{~mL}$, with a ligand concentration $\left(C_{\mathrm{L}}\right)$ of $6.7 \times 10^{-4} \mathrm{M}$, under different $C_{\mathrm{M}} / C_{\mathrm{L}}$ ratios: 0:1 $(\mathrm{L}), 1: 1$, and 1:2 $(\mathrm{M}=\mathrm{Cu}, \mathrm{Zn})$. All titrations were performed in duplicate and under the stated experimental conditions the $\mathrm{p} K_{\mathrm{w}}$ value (13.6) was determined and subsequently used in the computations. The stepwise protonation constant

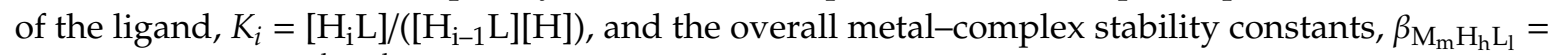
$\left[\mathrm{M}_{\mathrm{m}} \mathrm{H}_{\mathrm{h}} \mathrm{L}_{1}\right] /\left([\mathrm{M}]^{\mathrm{m}}[\mathrm{H}]^{\mathrm{h}}[\mathrm{L}]^{\mathrm{l}}\right)$, were calculated by fitting the potentiometric titration data with Hyperquad 2008 [26]. The metal hydrolysis constants were determined under the defined experimental conditions $\left(I=0.1 \mathrm{M} \mathrm{KCl}, 50 \% w / w \mathrm{DMSO} / \mathrm{H}_{2} \mathrm{O}, \mathrm{T}=25.0 \pm 0.1{ }^{\circ} \mathrm{C}\right)$ and the following values of stability constants were included in the fitting of experimental data towards the equilibrium models related to the $\mathrm{Cu}^{2+} / \mathrm{L}$ and $\mathrm{Zn}^{2+} / \mathrm{L}$ systems: $\log \beta_{\mathrm{Cu}_{2} \mathrm{H}_{-2}}=-9.99 ; \log \beta_{\mathrm{ZnH}_{-2}}=-14.79, \log \beta_{\mathrm{ZnH_{-3 }}}=-23.48$. Species distribution curves were plotted with the Hyss program [26].

\subsubsection{Cell Viability and Neuroprotection}

SH-SY5Y human neuroblastoma cell line (ATCC-CRL-2266) was cultured in Dulbecco's Modified Eagle Medium (DMEM) (Gibco-Invitrogen, Life Technologies Ltd., Liverpool, UK) supplemented with $10 \%$ of heat inactivated fetal bovine serum, $50 \mathrm{U} / \mathrm{mL}$ penicillin, and $50 \mu \mathrm{g} / \mathrm{mL}$ streptomycin, at $37^{\circ} \mathrm{C}$ in $5 \% \mathrm{CO}_{2}$. For the cell viability experiments, cells were plated with a density of $0.12 \times 10^{6}$ cells $/ \mathrm{mL}$. All the tested compounds (from 7 to 12) were dissolved in DMSO and aliquots were stored at $-20^{\circ} \mathrm{C}$ with a stock concentration of $25 \mathrm{mM}$. To choose the highest non-toxic concentration of the compounds, a 
concentration screening was performed (from $2.5 \mu \mathrm{M}$ to $10 \mu \mathrm{M}$ ). For the experiments, all the compounds were added to the medium at a final concentration of $2.5 \mu \mathrm{M}$. The concentration of DMSO in culture media did not exceed $0.05 \%(v / v)$ and no alterations were detected in the SH-SY5Y cell line. Cells were pre-incubated for $1 \mathrm{~h}$ with the compounds and then incubated with $\mathrm{A} \beta_{1-42}$ or with Fe/Asc for an additional $24 \mathrm{~h}$. A $\beta_{1-42}$ (Bachem, Torrance, CA, USA) stock with a concentration of $276.9 \mu \mathrm{M}$ was prepared in sterile water and a final concentration of $1 \mu \mathrm{M}$ was added to the culture medium. Both stock solutions of ferrous sulfate (Fe) and L-Ascorbic acid (Asc) (Sigma Chemical Co, St. Louis, MO, USA) were prepared in sterile water and $2.5 \mathrm{mM}$ of ferrous sulfate and $5 \mathrm{mM}$ of L-Ascorbic acid were added together to the culture medium. For all the experiments, control conditions were performed in which the compounds were tested and $\mathrm{A} \beta_{1-42}$ or Fe/Asc were not added.

Cell viability was determined using the colorimetric 3-(4,5-dimethylthiazol-2-yl)-2,5diphenyltetrazolium bromide (MTT) assay [56]. In viable cells, cellular dehydrogenases metabolize the MTT into a formazan that absorbs light at $570 \mathrm{~nm}$. After the incubations, the culture medium was aspirated and $0.3 \mathrm{~mL}$ of MTT $(0.5 \mathrm{mg} / \mathrm{mL})$ was added to each well. After incubation at $37^{\circ} \mathrm{C}$ for $3 \mathrm{~h}$, formazan precipitates were solubilized with $0.3 \mathrm{~mL}$ of acidic/isopropanol $(0.04 \mathrm{M} \mathrm{HCl} / \mathrm{Isopropanol})$. The absorbance of the plate was measured at $570 \mathrm{~nm}$. Cell reduction ability was normalized to untreated control cells.

All data were expressed as mean \pm SEM of at least four independent experiments performed in duplicates. Statistical analyses were performed using one-way ANOVA followed by Bonferroni multiple comparisons procedure post hoc test. $P$ value $<0.05$ was considered statistically significant.

\section{Conclusions}

Due to the complexity of AD pathogenesis and concomitant absence of cure, we have been engaged in the search for molecular entities capable of hitting multiple targets of this disease and thus being possibly explored as chemical tools against AD. The present strategy has been focused on the repositioning of approved drugs based on AChE inhibition, namely donepezil (DNP). Therefore, the MTDLs developed herein integrate mimetics of the active molecular fragment of DNP merged with other moieties, in order to combine the symptomatic amelioration by AChEi with other disease-modifying roles involved in amyloid plaque formation, namely inhibition of $\mathrm{A} \beta$ aggregation, as well as modulation of metal dyshomeostasis and oxidative stress. In particular, challenged by previous results with simple (DNP-BIM) conjugates (DNP mimetics coupled with a 2-hydroxyphenylbenzimidazole (BIM)), the present work exploited the effect on the activity of some structural modifications, namely by positional isomerization and substituent introduction. Regarding the positional isomers $(3,4,5)$ of compound $\mathbf{1}$, there is a general slight decrease of the AChEi activity, namely for compound 4, due to some apparent structural distortion, although they keep identical capacity to inhibit $\mathrm{A} \beta$ aggregation. All the compounds are able to chelate metal ions through their BIM moieties and, remarkably, isomer 5, due to the closeness of the carbonyl to the bidentate BIM unity provides a three-dentate chelating moiety, having higher capacity for copper chelation. This may be responsible for the more than $50 \%$ increase on $\mathrm{Cu}$-induced $\mathrm{A} \beta$ aggregation relative to the self-induced one observed for 5 . Concerning the effect of the substituents on the cholinergic activity, the best results were obtained for the conjugates with the fluorine atom in each moiety $(6,8$ and 10$)$ and also with the metoxyl group in the benzyl ring (9), while lowest activity was revealed by the compounds with the nitro substituents $(7,11)$, but the worst results were obtained for the pyridinium derivative (12). Regarding the effect of a selection of DNP-BIM hybrids in neuroblastoma cells, compounds $\mathbf{9}$ and $\mathbf{1 0}$ showed a remarkable reduction of A $\beta$-induced cell toxicity, although none of the tested compounds presented a statistically significant neuroprotective effect by preventing ROS production. Overall, among these DNP-BIM hybrids, structural isomerization did not bring general improvement of properties; regarding the substituent modification, excluding the nitro-substituted and pyridinium derivatives, a set of substituted conjugates, namely methoxy and fluorine substituent groups, showed very good properties and so they deserve to be further explored in the development of new hybrids aimed at the discovery of novel anti-AD drugs. 
Supplementary Materials: The following are available online, Figure S1: Redocking of original ligand (DNP) from PDB code 1EVE [1], inside the TcAChE active site, under the same simulation conditions used for the docking of the ligands in the present study.

Author Contributions: Conceptualization, M.A.S., S.C., L.P.; formal analysis, S.C., S.R., F.R., M.C., R.J., K.G., A.R.P.-S.; investigation, S.R., F.R., M.C., R.J., K.G., A.R.P.-S.; data curation, S.C., M.A.S., S.M.C.; writing-original draft preparation, M.A.S., S.C., S.R., F.R., M.C., S.M.C.; writing-review and editing, M.A.S., S.C.; supervision, M.A.S., S.C., L.P., S.M.C.; project administration, M.A.S., S.C., V.C.; funding acquisition, M.A.S., S.C., V.C. All authors have read and agreed to the published version of the manuscript.

Funding: This research was funded by the Portuguese Fundação para a Ciência e Tecnologia (FCT), projects UID/QUI/00100/2013 and UID/QUI/00100/2019, and F.R., S.R., K.G. and R.J. were funded by Europe Erasmus+ program. It was also funded by the European Regional Development Fund (ERDF), through the Centro 2020 Regional Operational Programme under project CENTRO-01-0145-FEDER-000012 (HealthyAging2020) and through the COMPETE 2020-Operational Programme for Competitiveness and Internationalisation and Portuguese national funds via FCT, under project POCI-01-0145-FEDER-030712 and UID/NEU/04539/2019.

Acknowledgments: The authors acknowledge FCT for the research funding and also the Portuguese NMR (IST-UL Center) and Mass Spectrometry Networks (Node IST-CTN) for providing access to their facilities.

Conflicts of Interest: The authors have no conflicting interests. The founding sponsors had no role in the design of the study, in the interpretation of data, in the writing of the manuscript, and in the decision to publish the results.

\section{References}

1. Alzheimer's Association. Alzheimer's disease facts and figures. Alzheimer's Dement. 2019, 15, 321-387.

2. Cummings, J.L.; Morstorf, T.; Zhong, K. Alzheimer's disease drug-development pipeline: Few candidates, frequent failures. Alzheimers Res. 2014, 6, 37. [CrossRef]

3. Anderson, R.M.; Hadjichrysanthou, C.; Evans, S.; Wong, M.M. Why do so many clinical trials of therapies for Alzheimer's disease fail? Lancet 2017, 390, 2327-2329. [CrossRef]

4. Tricco, A.C.; Ashoor, H.M.; Soobiah, C.; Rios, P.; Veroniki, A.A.; Hamid, J.S.; Ivory, J.D.; Khan, P.A.; Yazdi, F.; Ghassemi, M.; et al. Comparative effectiveness and safety of cognitive enhancers for treating Alzheimer's disease: Systematic review and network metaanalysis. J. Am. Geriatr. Soc. 2018, 66, 170-178. [CrossRef]

5. Savelieff, M.; Nam, G.; Kang, J.; Lee, H.J.; Lee, M.; Lim, M.H. Development of multifunctional molecules as potential therapeutic candidates for Alzheimer's disease, Parkinson's disease and amyotrophic lateral sclerosis in the last decade. Chem. Rev. 2019, 119, 1221-1322. [CrossRef]

6. Marco-Contelles, J. Facts, results and perspectives of the current Alzheimer's disease research. ACS Chem. Neurosci. 2019, 10, 1127-1128. [CrossRef]

7. Piemontese, L.; Loiodice, F.; Chaves, S.; Santos, M.A. The therapy of Alzheimer's disease: Towards a new generation of drugs. Front. Clin. Drug Res. Alzheimer Dis. 2019, 8, 33-80.

8. Prati, F.; Bottegoni, G.; Bolognesi, M.L.; Cavalli, A. BACE-1 Inhibitors: From recent single-target molecules to multitarget compounds for Alzheimer's disease. J. Med. Chem. 2018, 61, 619-637. [CrossRef]

9. Guzior, N.; Wieckowska, A.; Panek, D.; Malawska, B. Recent development of multifunctional agents as potential drug candidates for the treatment of Alzheimer's disease. Curr. Med. Chem. 2015, 22, 373-404. [CrossRef]

10. Santos, M.A.; Chand, K.; Chaves, S. Recent progress in repositioning Alzheimer's disease drugs based on a multitarget strategy. Fut. Med. Chem. 2016, 8, 2113-2142. [CrossRef]

11. Dudley, J.; Berliocchi, L. Drug Repositioning: Approaches and Applications for Neurotherapeutics; CRC Press, Taylor \& Francis Group: Boca Raton, FL, USA, 2017; ISBN 9781315373669.

12. Castro, A.A.; Cunha, E.F.F.; Pereira, A.F.; Soares, F.V.; Leala, D.H.S.; Kuca, K.; Ramalho, T.C. Insights into the drug repositioning applied to the Alzheimer's disease treatment and future perspectives. Curr. Alzheimer Res. 2018, 15, 1-18. [CrossRef]

13. Mezeiova, E.; Spilovska, K.; Nepovimova, E.; Gorecki, L.; Soukup, O.; Dolezal, R.; Malinak, D.; Janockova, J.; Jun, D.; Kuca, K.; et al. Profiling donepezil template into multipotent hybrids with antioxidant properties. J. Enz. Inhib. Med. Chem. 2018, 33, 583-606. [CrossRef]

14. Mezeiova, E.; Chalupova, K.; Nepovimova, E.; Gorecki, L.; Prchal, L.; Malinak, D.; Kuca, K.; Soukup, O.; Korabecny, J. Donepezil Derivatives Targeting Amyloid- $\beta$ Cascade in Alzheimer's Disease. Curr. Alzheimer Res. 2019, 16, 772-800. [CrossRef] 
15. Barnham, K.J.; Bush, A.I. Biological metals and metal-targeting compounds in major neurodegenerative diseases. Chem. Soc. Rev. 2014, 43, 6727-6749. [CrossRef]

16. Faller, P.; Hureau, C.; Berthoumieu, O. Role of metal ions in the self-assembly of the Alzheimer's amyloid Ab peptide. Inorg. Chem. 2013, 52, 12193-12206. [CrossRef]

17. Nam, G.; Lim, M.H. Intertwined Pathologies of Amyloid- $\beta$ and Metal Ions in Alzheimer's Disease: Metal-Amyloid- $\beta$. Chem. Lett. 2019, 48, 951-960. [CrossRef]

18. Sales, T.A.; Prandi, I.G.; de Castro, A.A.; Leal, D.H.S.; Cunha, E.F.F.; Kuca, K.; Ramalho, T.C. Recent Developments in Metal-Based Drugs and Chelating Agents for Neurodegenerative Diseases Treatments. Int. J. Mol. Sci. 2019, 20, 1829. [CrossRef]

19. Santos, M.A.; Chand, K.; Chaves, S. Recent progress in multifunctional metal chelators as potential drugs for Alzheimer's disease. Coord. Chem. Rev. 2016, 327-328, 287-303. [CrossRef]

20. Chand, K.; Rajeshwari; Chaves, S.; Santos, M.A. Tacrine-deferiprone hybrids as multi-target-directed metal chelators against Alzheimer's disease: A two-in-one drug. Metallomics 2018, 10, 1460-1475. [CrossRef]

21. Gaia, F.; Karam, C.; Tomás, D.; Orlandini, E.; Piemontese, L.; Silva, D.F.; Cardoso, S.M.; Chaves, S.; Santos, M.A. Novel Tacrine-Benzofuran hybrids as potential multi-target drug candidates for the treatment of Alzheimer's Disease. J. Enz. Inhib. Med. Chem. 2020, 35, 211-226.

22. Hiremathad, A.; Keri, R.S.; Esteves, A.R.; Cardoso, S.M.; Chaves, S.; Santos, M.A. Novel TacrineHydroxyphenylbenzimidazole hybrids as potential multitarget drug candidates for Alzheimer's disease. Eur. J. Med. Chem. 2018, 148, 255-267. [CrossRef]

23. Piemontese, L.; Tomás, D.; Hiremathad, A.; Capriati, V.; Candeias, E.; Cardoso, S.M.; Chaves, S.; Santos, M.A. Donepezil structure-based hybrids as potential multifunctional anti-Alzheimer's drug candidates. J. Enzym. Inhib. Med. Chem. 2018, 33, 1212-1224. [CrossRef]

24. Kryger, G.; Silman, I.; Sussman, J.L. Structure of acetylcholinesterase complexed with E2020 (Aricept): Implications for the design of new anti-Alzheimer drugs. Struct. Fold. Des. 1999, 7, 297-307. [CrossRef]

25. Piemontese, L.; Sergio, R.; Rinaldo, F.; Brunetti, L.; Perna, F.M.; Santos, M.A.; Capriati, V. Deep eutectic solvents as effective reaction media for the synthesis of 2-hydroxyphenylbenzimidazole-based scaffolds en route to Donepezil-like Compounds. Molecules 2020, 25, 574. [CrossRef]

26. Gans, P.; Sabatini, A.; Vacca, A. Investigation of equilibria in solution. Determination of equilibrium constants with the HYPERQUAD suite of programs. Talanta 1996, 43, 1739-1753. [CrossRef]

27. Liptak, M.D.; Gross, K.C.; Seybold, P.G.; Feldgus, S.; Shields, G.C. Absolute pKa determinations for substituted phenols. J. Am. Chem. Soc. 2002, 124, 6421-6427. [CrossRef]

28. Smith, R.M.; Martell, A.E. Bibliography. In Critical Stability Constants; Plenum Press: New York, NY, USA; London, UK, 1989; Volume 6, p. 493.

29. Smith, R.M.; Martell, A.E. Azines. In Critical Stability Constants; Plenum Press: New York, NY, USA; London, UK, 1989; Volume 6, p. 258.

30. Walba, H.; Isensee, R.W. Acidity constants of some arylimidazoles and their cations. J. Org. Chem. 1961, 26, 2789-2791. [CrossRef]

31. Costa, M.; Josselin, R.; Silva, D.F.; Cardoso, S.M.; May, N.V.; Chaves, S.; Santos, M.A. Donepezil-Based Hybrids as Multifunctional Anti-Alzheimer's Disease Chelating Agents: Effect of Positional Isomerization. J. Inorg. Biochem. 2020. under publication. [CrossRef]

32. Raymond, K.N.; Carrano, C.J. Coordination chemistry and microbial iron transport. ACC Chem. Res. 1979, 12, 183-190. [CrossRef]

33. Chaves, S.; Hiremathad, A.; Tomás, D.; Keri, R.S.; Piemontese, L.; Santos, M.A. Exploring the chelating capacity of 2-hydroxyphenyl-benzimidazole based hybrids with multi-target ability as anti-Alzheimer's agents. New J. Chem. 2018, 42, 16503-16515. [CrossRef]

34. Ellman, G.L.; Courtney, K.D.; Andres, V., Jr.; Feather-Stone, R.M. A new and rapid colorimetric determination of acetylcholinesterase activity. Biochem. Pharm. 1961, 7, 88-95. [CrossRef]

35. Tan, C.C.; Yu, J.T.; Wang, H.F.; Tan, M.S.; Meng, X.F.; Wang, C.; Jiang, T.; Zhu, X.C.; Tan, L. Efficacy and safety of donepezil, galantamine, rivastigmine, and memantine for the treatment of Alzheimer's disease: A systematic review and meta-analysis. J. Alzheimer's Dis. 2014, 41, 615-631. [CrossRef]

36. Bartolini, M.; Bertucci, C.; Bolognesi, M.L.; Cavalli, A.; Melchiorre, C.; Andrisano, V. Insight into the kinetic of amyloid beta (1-42) peptide self-aggregation: Elucidation of inhibitors' mechanism of action. ChemBioChem 2007, 8, 2152-2161. [CrossRef] 
37. Chao, X.; He, X.; Yang, Y.; Zhou, X.; Jin, M.; Liu, S.; Cheng, Z.; Liu, P.; Wang, Y.; Yu, J.; et al. Design, synthesis and pharmacological evaluation of novel tacrine-caffeic acid hybrids as multi-targeted compounds against Alzheimer's disease. Bioorg. Med. Chem. Lett. 2012, 22, 6498-6502. [CrossRef]

38. Mold, M.; Ouro-Gnao, L.; Wieckowski, B.; Exley, C. Copper prevents amyloid- $\beta_{1-42}$ from forming amyloid fibrils under near-physiological conditions in vitro. Sci. Rep. 2013, 3, 1256. [CrossRef]

39. Tahmasebinia, F.; Emadi, S. Effect of metal chelators on the aggregation of beta-amyloid peptides in the presence of copper and iron. Biometals 2017, 30, 285-293. [CrossRef]

40. Gestwicki, J.E.; Ranke, A. Structure-activity relationships of amyloid beta-aggregation inhibitors based on curcumin: Influence of linker length and flexibility. Chem. Biol. Drug Des. 2007, 70, 206-215.

41. Faller, P.; Hureau, C. Bioinorganic chemistry of copper and zinc ions coordinated to amyloid- $\beta$ peptide. Dalton Trans. 2009, 7, 1080-1094. [CrossRef]

42. Silva, D.F.; Selfridge, J.E.; Lu, E.L.; Cardoso, S.M.; Swerdlow, R.H. Mitochondrial abnormalities in Alzheimer's disease: Possible targets for therapeutic intervention. Adv. Pharmacol. 2012, 64, 83-126.

43. QikProp, Version 2.5; Schrödinger LLC: New York, NY, USA, 2005.

44. Lipinski, C.A.; Lombardo, F.; Dominy, B.W.; Feeney, P.J. Experimental and computational approaches to estimate solubility and permeability in drug discovery and development settings. Adv. Drug Deliv. Rev. 1997, 23, 3-26. [CrossRef]

45. Armarego, W.L.F.; Perrin, D.D. Purification of Laboratory Chemicals, 4th ed.; Butterworth-Heinemann; Oxford Press: Oxford, UK, 1999.

46. Jones, G.; Willett, P.; Glen, R.C.; Leach, A.R.; Taylor, R. Development and validation of a genetic algorithm for flexible docking. J. Mol. Biol. 1997, 267, 727-748. [CrossRef] [PubMed]

47. Cheung, J.; Rudolph, M.J.; Burshteyn, F.; Cassidy, M.S.; Gary, E.N.; Love, J.; Franklin, M.C.; Height, J.J. Structures of Human acetylcholinesterase in complex with pharmacologically important ligands. J. Med. Chem. 2012, 55, 10282-10286. [CrossRef] [PubMed]

48. Maestro, Version 9.3; Schrödinger Inc.: Portland, OR, USA, 2012.

49. Hassinen, T.; Peräkylä, M. New energy terms for reduced protein models implemented in an off-lattice force field. J. Comput. Chem. 2001, 22, 1229-1242. [CrossRef]

50. Acton, A.; Banck, M.; Bréfort, J.; Cruz, M.; Curtis, D.; Hassinen, T.; Heikkilä, V.; Hutchison, G.; Huuskonen, J.; Jensen, J.; et al. Ghemical Version 3.0; Bioinformatics.org: Biglerville, PA, USA, 2011.

51. Pettersen, E.F.; Goddard, T.D.; Huang, C.C.; Couch, G.S.; Greenblatt, D.M.; Meng, E.C.; Ferrin, T.E. UCSF Chimera-A visualization system for exploratory research and analysis. J. Comput. Chem. 2004, 25, 1605-1612. [CrossRef]

52. Quintanova, C.; Keri, R.S.; Marques, S.M.; Fernandes, M.G.; Cardoso, S.M.; Serralheiro, M.L.; Santos, M.A. Design, synthesis and bioevaluation of tacrine hybrids with cinnamate and cinnamylidene acetate derivatives as potential anti-Alzheimer drugs. MedChem Comm 2015, 6, 1969-1977. [CrossRef]

53. Šebestík, J.; Marques, S.M.; Falé, P.L.; Santos, S.; Arduíno, D.M.; Cardoso, S.M.; Oliveira, C.R.; Serralheiro, M.L.M.; Santos, M.A. Bifunctional phenolic-choline conjugates as anti-oxidants and acetylcholinesterase inhibitors. J. Enzym. Inhib. Med. Chem. 2011, 26, 485-497. [CrossRef]

54. Hiremathad, A.; Chand, K.; Esteves, A.R.; Cardoso, S.M.; Ramsay, R.R.; Chaves, S.; Keri, R.S.; Santos, M.A. Tacrine-allyl/propargylcysteine-benzothiazole trihybrids as potential anti-Alzheimer's drug candidates. RSC Adv. 2016, 6, 53519-53532. [CrossRef]

55. Rossotti, F.J.C.; Rossotti, H. Potentiometric titrations using Gran plots: A textbook omission. J. Chem. Ed. 1965, 42, 375-378. [CrossRef]

56. Mosmann, T. Rapid colorimetric assay for cellular growth and survival: Application to proliferation and cytotoxicity assays. J. Immunol. Methods 1983, 65, 55-63. [CrossRef]

Sample Availability: Not available.

(C) 2020 by the authors. Licensee MDPI, Basel, Switzerland. This article is an open access article distributed under the terms and conditions of the Creative Commons Attribution (CC BY) license (http://creativecommons.org/licenses/by/4.0/). 